\title{
Intestinal barrier dysfunction: implications for chronic inflammatory conditions of the bowel
}

\author{
Warren M. Miner-Williams ${ }^{1,2}$ and Paul J. Moughan ${ }^{1 *}$ \\ ${ }^{1}$ Riddet Institute, Massey University, Private Bag 11-222, Palmerston North, New Zealand \\ ${ }^{2}$ School of Clinical Sciences, Faculty of Health and Environmental Sciences, AUT University, 90 Akoranga Drive, Northcote, \\ Auckland, 0627, New Zealand
}

Abstract

The intestinal epithelium of adult humans acts as a differentially permeable barrier that separates the potentially harmful contents of the lumen from the underlying tissues. Any dysfunction of this boundary layer that disturbs the homeostatic equilibrium between the internal and external environments may initiate and sustain a biochemical cascade that results in inflammation of the intestine. Key to such dysfunction are genetic, microbial and other environmental factors that, singularly or in combination, result in chronic inflammation that is symptomatic of inflammatory bowel disease (IBD). The aim of the present review is to assess the scientific evidence to support the hypothesis that defective transepithelial transport mechanisms and the heightened absorption of intact antigenic proinflammatory oligopeptides are important contributing factors in the pathogenesis of IBD.

Key words: Absorption: Gastrointestinal tract: Crohn's disease: Ulcerative colitis: Inflammatory bowel disease: Microbiota: Immune system

\section{Introduction}

The intestinal lumen contains a multitude of exogenous substances that include dietary antigens and micro-organisms, both commensal and sometimes pathogenic. The intestinal epithelium acts as interface and regulator, a selective barrier that separates the luminal contents from the underlying connective tissue of the host. The immune system safeguards the host from the translocation of harmful foreign substances and helps maintain the homeostatic balance between the internal and external environments of the intestinal tract ${ }^{(1)}$. Inflammatory bowel disease (IBD) is a chronic condition that involves the disturbance of this balance.

IBD is comprised of a spectrum of disorders which include Crohn's disease (CD) and ulcerative colitis (UC), chronic remittent or progressive disorders characterised by non-specific inflammation and intestinal tissue damage. The pathogenesis of IBD involves complex dysregulated interactions between various factors, with genetic predisposition, the intestinal microbiota and innate and adaptive immune responses appearing to be key elements. While Khan et al. ${ }^{(2)}$ suggest that the failure of at least one component of this triad is sufficient to trigger the inflammatory changes necessary for the induction of IBD, other researchers disagree, claiming that genetic dysfunction of the intestinal innate immune system is a key precursor of the disease ${ }^{(3-6)}$. Gruber et al. ${ }^{(7)}$ state that the pathogenesis of IBD, its onset and its recurrence, is most likely triggered by unknown environmental agents ${ }^{(7,8)}$. Many researchers have implicated other factors, such as the dysfunction of intercellular transport mechanisms, for example, PepT1 ${ }^{(9-11)}$, together with factors involved in the exacerbation of IBD such as diet ${ }^{(12-15)}$, cigarette smoking ${ }^{(16)}$, stress ${ }^{(17)}$, food additives $^{(7)}$ and microbial dysbioses ${ }^{(18)}$. Although the course of the disease is variable, it commonly affects the intestinal mucosa and leads to both structural and functional impairment. In genetically susceptible individuals, a disturbed host-bacterial relationship leads to immunopathological changes in the mucosa that continue in chronic remitting-relapsing cycles ${ }^{(2)}$.

$\mathrm{CD}$ is an inflammatory condition associated with increased intestinal permeability ${ }^{(19,20)}$, indicating a disturbance of the epithelial barrier, and may affect one or multiple areas of the intestinal tract, from mouth to anus ${ }^{(21)}$. It is unclear whether increased intestinal permeability precedes and contributes to intestinal inflammation ${ }^{(22)}$ or is a result of the inflammatory process $^{(23,24)}$. CD has been described as being associated with Western societies that are 'pathogen poor', whereas in developing countries, cases of idiopathic IBD such as CD are rare $^{(25)}$. UC is an aggravated inflammatory response with

Abbreviations: CD; Crohn's disease; CeD; coeliac disease; EEN; exclusive enteral nutrition; EPEC; enteropathogenic Escherichia coli; fMLP; N-formylmethionylleucyl-phenylalanine; IAP; intestinal alkaline phosphatase; IBD; inflammatory bowel disease; IFN- $\gamma$; interferon- $\gamma$; MDP; muramyl dipeptide; MMP; matrix metalloproteinase; MUC2; mucin 2; NOD; nucleotide-binding oligomerisation domain; SIgA; secretory IgA; TJ; tight junction; Tri-DAP; 1 -Ala- $\gamma$-dGlu-meso-diaminopimelic acid; TRUC; ${\mathrm{T}-\mathrm{bet}^{-/-}}^{-1} \mathrm{Rag}^{-/-} \mathrm{UC}$; UC; ulcerative colitis.

* Corresponding author: Professor P. J. Moughan, email p.j.moughan@massey.ac.nz 
accompanying ulceration of the colon, thought to result from the absorption of chemotactic bacterial peptides ${ }^{(26)}$.

The intestinal tract of the mammalian neonate is permeable to large peptides and other molecules, allowing the absorption of intact immunoactive molecules from milk to supplement the immature immune system ${ }^{(27-31)}$. The permeability of the intestinal epithelium to these larger molecules normally ceases in the post-weaned mammal. If such permeability continues it may be a possible trigger of IBD. The absorption of intact macromolecules from the healthy intestine remains a controversial issue, as there is little unequivocal in vivo evidence (other than antigen sampling) demonstrating this phenomenon $^{(32)}$. However, macromolecules, and indeed microbes, can be absorbed by the mucosal tissues via transport systems that predominantly involve the adaptive and innate immune responses of the intestinal mucosa and which are key to the absorption of proinflammatory proteins/peptides in IBD.

The aim of the present review is to assess the scientific evidence to support the hypothesis that defective transepithelial transport mechanisms and the increased absorption of antigenic proinflammatory oliogopeptides are important contributing factors in the pathogenesis of IBD.

\section{Disruption to the intestinal environment \\ Epithelial barrier dysfunction}

The intestinal epithelium regulates the flow of nutrients, ions and water between the lumen and underlying tissues, limiting contact between the host and the intraluminal quantities of exogenous antigens and microbes. In a healthy subject, the transepithelial transport of small amounts of food- and microbial-antigens participates in the induction of a homeostatic immune response that allows immune tolerance to such antigens $^{(33,34)}$, preventing the internalisation of both pathogenic and commensal microbes ${ }^{(28)}$. However, epithelial barrier dysfunction can lead to the entry of excessive dietary or microbe-derived macromolecules, which are putative contributors to the pathogenesis of a spectrum of human diseases including food allergies, coeliac disease (CeD), IBD, autoimmune diseases and the metabolic syndrome ${ }^{(35,36)}$. Improving intestinal barrier function, particularly the paracellular pathway, may form a therapeutic strategy for the treatment or prevention of diseases driven by luminal antigens. Understanding how antigens are transported across the epithelium in both healthy and diseased states may assist in the development of appropriate therapies ${ }^{(28)}$.

The transport of molecules across the intestinal mucosa occurs through two distinct mechanisms: paracellular diffusion through tight junctions (TJ) between adjacent intestinal epithelial cells, and transcellular transport involving the transcytosis of materials which may or may not be mediated by membrane receptors (illustrated in Fig. 1).

\section{Paracellular transport}

The paracellular pathway involves structures joining adjacent intestinal epithelial cells and delineated by $\mathrm{TJ}$, adherens

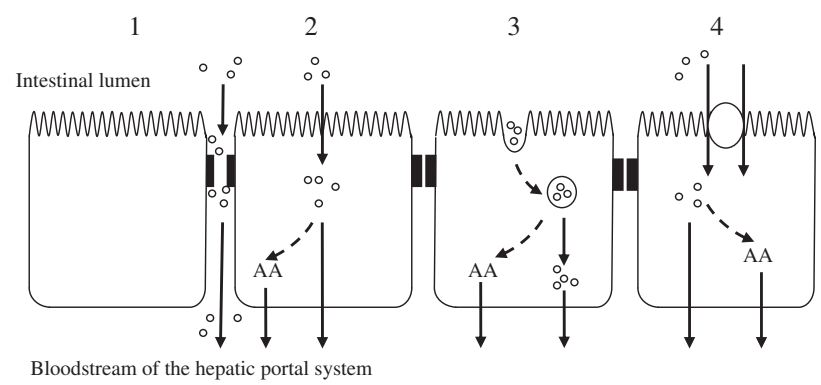

Fig. 1. Potential mechanisms of enterocytic uptake of peptides. (1) Paracellular: increased permeability of tight junctions may permit the passage of peptides. (2) Passive diffusion: cell-penetrating peptides are capable of transporting peptides as cargo. (3) Endocytosis: followed by endosomal release of the peptides. (4) Carrier-mediated transport: transport via the intestinal peptide transporter PEPT1 $\left(\mathrm{H}^{+} / \mathrm{di}\right.$ - and tri-peptide symporter). Inside the enterocyte peptides can be hydrolysed to their constituent amino acids (AA) and transported across the basolateral membrane by specific AA transporters. It is thought that the transport of peptides across the basolateral membrane is mediated through other transporters such as those suggested by Terada et al..$^{(322,323)}$, Shepherd et al. ${ }^{(324)}$ and Irie et al. ${ }^{(325)}$.

junctions and desmosomes ${ }^{(28)}$. The rate-limiting factor in the paracellular diffusion of molecules are the TJ, a network of transmembrane proteins (claudins ${ }^{(37)}$, occludin ${ }^{(38)}$, junctional adhesion molecule $\mathrm{A}^{(39)}$ and tricellulin ${ }^{(40)}$ ) which control the TJ plasticity and permeability. TJ form pores that range in diameter between 0.4 and $0.9 \mathrm{~nm}$ to 5 and $6 \mathrm{~nm}$ in villi or crypts, respectively. Occludin interacts with the zonula occludens proteins ( $\mathrm{ZO}-1, \mathrm{ZO}-2$ ) that regulate the actomyosin ring. TJ allow the diffusion of mostly cations and inert small molecules less than $600 \mathrm{Da}$ such as water-soluble peptides ${ }^{(41)}$.

Increased paracellular permeability has been observed in IBD together with abnormal TJ structure and a down-regulation and redistribution of several $\mathrm{TJ}$ proteins or the subjacent adherens junction proteins ${ }^{(42,43)}$. A variety of pathological conditions can increase paracellular permeability in which molecules of greater size can diffuse non-specifically across the intestinal epithelial layer ${ }^{(28)}$. The involvement of proinflammatory cytokines in the pathophysiology of IBD is well recognised $^{(44,45)}$, and these cytokines are implicated in epithelial barrier dysfunction that leads to increased intestinal permeability along paracellular pathways ${ }^{(28)}$. Both interferon- $\gamma$ (IFN- $\gamma$ ) and TNF- $\alpha$ are elevated in the mucosa of IBD patients and contribute to a proinflammatory cascade that includes barrier disruption ${ }^{(46,47)}$. Bruewer et al. ${ }^{(48)}$ have shown that the specificity of these mediators for the disruption of specific intercellular junctional proteins under inflammatory conditions is indicated, as the junctional proteins remained unaltered in non-inflamed areas of diseased tissue. Some of the mechanisms underlying the structural and functional modifications of $\mathrm{TJ}$ include the endocytosis of junctional proteins ${ }^{(49,50)}$, epithelial apoptosis $^{(51-53)}$, reduced transcription of TJ proteins ${ }^{(54)}$ and the activation of myosin light-chain kinase phosphorylation to promote cytoskeletal contraction ${ }^{(55)}$. Menard et al. ${ }^{(28)}$ suggest that myosin light-chain kinase is a key molecule that stimulates the opening of TJ by phosphorylating the myosin light chains. Increased claudin-2 expression increases the number of pores that allow the paracellular movement of small molecules. 
Myosin light-chain kinase activation and occludin downregulation increase paracellular transport that is characteristic of both UC and $\mathrm{CD}^{(56)}$.

Probiotics are live bacteria which improve the health of the host beyond their inherent nutritional value ${ }^{(57)}$. It has been hypothesised that probiotics have anti-inflammatory effects in human IBD and preserve intestinal epithelial integrity ${ }^{(58)}$. A number of in vitro studies using epithelial monolayers have demonstrated that probiotics have improved epithelial barrier function following Escherichia coli infection or incubation with proinflammatory cytokines ${ }^{(59-62)}$. Several in vivo studies have demonstrated that probiotic therapy may change the expression of TJ proteins ${ }^{(57,63)}$ and decrease paracellular permeability by increasing the phosphorylation of TJ proteins, such as ZO-1, claudin-1, or occludin in dextran-sodium sulfate-induced colitis (acute model) mice $57,63,64)$ and $\mathrm{IL}-10^{-/-}$(chronic model) mice $^{(65,66)}$. However, the underlying molecular mechanisms by which probiotics diminish paracellular permeability remain unclear $^{(65)}$.

\section{Transcellular transport}

The transcellular transport of large particles, including microbes, has been ascribed to $M$ cells located in the follicleassociated epithelium of Peyer's patches ${ }^{(28)}$ and isolated lymphoid follicles in the distal part of the intestine ${ }^{(67,68)}$. Dendritic cells may sample bacteria in the intestinal lumen by extending dendrites between adjacent epithelial cells ${ }^{(69)}$.

Lipid-soluble oliogopeptides may enter the enterocytes by passive diffusion where they are susceptible to hydrolytic degradation by cytosolic enzymes ${ }^{(41)}$. As large polar molecules (for example, peptide fragments $>600 \mathrm{Da}$ ) cannot pass through the hydrophobic cell membrane of the enterocyte they may be captured by invagination of the apical membrane. Such vesicles normally fuse with lysosomes to form phagolysosomes, in which enzymic digestion of the macromolecules occurs. Only protein that escapes hydrolysis within these structures can be drawn through the enterocytes and cross the basolateral membrane.

The transcytosis of internalised vesicles may carry specifically bound ligands (receptor-mediated transcytosis), non-specifically adsorbed ligands (adsorptive transcytosis) or fluids (fluid-phase transcytosis) from the apical membrane across the cell to the basolateral membrane ${ }^{(70,71)}$.

Epithelial cells of the intestinal mucosa also sample large molecules greater than $600 \mathrm{Da}$ in size (such as food antigens) by endocytosis at the apical membrane and transcytosis toward the lamina propria. Within the epithelial cell, proteins/peptides are digested in acidic and lysosomal compartments before being released as amino acids or partly degraded products at the basolateral pole of the enterocytes ${ }^{(28)}$. Partially degraded food antigens in early endosomes bind to major histocompatibility complex (MHC) class II molecules in an intracellular endocytotic compartment (MIIC). Inward invagination of MIIC compartments leads to the formation of exosomes, small membrane vesicles $(40-90 \mathrm{~nm}$ ) bearing MHC class II/peptide complexes at their surface ${ }^{(28)}$. Antigen-loaded exosomes can then fuse with the basement membrane before being released into the extracellular medium to interact with local immune cells ${ }^{(72)}$. Exosome-bound peptides are much more potent than free peptides to interact with dendritic cells and stimulate peptide presentation to $\mathrm{T}$ cells ${ }^{(73)}$.

IgA is a dimeric protective mucosal immunoglobulin secreted into the intestinal lumen as secretory $\operatorname{IgA}(\mathrm{SIgA})$, and is the most representative immunoglobulin at the mucosal surface. The major role of SIgA in healthy subjects is to restrict potentially harmful food and microbial antigens from entering the intestinal epithelia ${ }^{(74)}$. However, in some pathological conditions the abnormal apical-to-basal retrotransport of SIgA immune complexes can mediate the entry of noxious antigens into the intestinal epithelial cells ${ }^{(28)}$. In CeD, an enteropathy induced by the abnormal activation of $\mathrm{T}$ cells by gluten-derived gliadin peptides, SIgA allows the transcytosis of IgA-gliadin immune complexes through the intestinal barrier via the transferrin receptor $\mathrm{CD} 71$ at the apical surface ${ }^{(75)}$. In healthy individuals this receptor is confined to the basolateral membrane and gliadin peptides are taken up by non-specific endocytosis and almost exclusively degraded by the intestinal epithelia. In active CeD the retrotransport of IgA-gliadin immune complexes most likely triggers exacerbated adaptive and innate immune responses that result in mucosal lesions ${ }^{(28)}$.

Significant quantities of IgG are also secreted at the mucosal surface which suggests a protective role. The transcytosis of IgG is mediated via the neonatal Fc receptor at the surface of intestinal epithelial cells in an acidic environment. At the basolateral side of the enterocyte the neutral $\mathrm{pH}$ induces the dissociation of $\mathrm{IgG}$ immune complexes from the receptor. Although the role of the neonatal Fc receptor in humans has not been established, it has been reported to mediate passive immunity in suckling rats from the maternal milk ${ }^{(76,77)}$. Bacteria as well as food antigens can be transported as IgG immune complexes via neonatal $\mathrm{Fc}$ receptors, a mechanism that is most likely involved in the defence against intestinal pathogens ${ }^{(28)}$, and a process that has been reported for commensal E. coli $^{(78)}$. However, the entry of bacteria or degraded bacterial components (for example, flagellin ${ }^{(79)}$ ) might precipitate an inappropriate immune response such as chronic inflammation ${ }^{(28)}$.

The overexpression of $\mathrm{CD} 23$, the low-affinity receptor for IgE, has been detected on both the apical and basolateral membranes of patients with gastrointestinal diseases such as IgE-dependent bovine milk allergy and enteropathy, autoimmune enteropathy, CD and $\mathrm{UC}^{(80)}$. Such an overexpression of $\mathrm{CD} 23$ at the apical surface of enterocytes can drive the transport of IgE-allergen immune complexes from the intestinal lumen (bypassing lysosomal degradation) to the lamina propria, which then triggers mast cell degranulation and the rapid onset of an allergic inflammatory response in subepithelial immunoreactive cells ${ }^{(28)}$.

Soderholm et al. ${ }^{(21)}$ were the first to demonstrate that proteinsized macromolecules can permeate, at an increased rate, the non-inflamed ileal mucosa of patients with CD. Although they had previously demonstrated that molecular leakage can be induced by TJ dysfunction in patients with $\mathrm{CD}^{(81)}$, later studies indicated that the increased endosomal uptake of antigens was mediated by the proinflammatory cytokine TNF- $\alpha$, which plays 
a pivotal role in $\mathrm{CD}$ pathogenesis. This demonstrates the importance of the transcellular route of antigen uptake in the barrier dysfunction of $\mathrm{CD}$, and underlines the importance of immune-epithelial interaction in the development of mucosal inflammation $^{(82)}$, which suggests that anti-TNF- $\alpha$ therapy may produce positive effects in patients suffering from $\mathrm{CD}^{(83)}$.

Another cytokine abundant in CD is IFN- $\gamma$. This cytokine is also thought to enhance the transcytosis of macromolecules and was first demonstrated by Terpend et al. in 1998 using ${ }^{3} \mathrm{H}$-labelled horseradish peroxidase in an in vitro intestinal epithelial model. This suggests that IFN- $\gamma$ may enhance both paracellular and transcellular leakage ${ }^{(84)}$.

Antigen transcytosis into endocytic cell compartments and finally into the cytosol is strongly enhanced in rapid antigen uptake into the cytosol enterocyte (RACE) cells of patients with CD and UC. This suggests that in the inflamed intestine both paracellular and transcellular transport pathways are increased and contribute to overstimulation of the local immune system. Such overstimulation creates a vicious cycle in which luminal antigens reach the lamina propria, interact with subepithelial immunoreactive cells, and drive the secretion of permeabilityenhancing factors that further increase epithelial barrier dysfunction $^{(28)}$.

\section{The microbiota}

The host and intestinal microbiota are in a state of symbiotic mutualism, forming what Goodacre ${ }^{(85)}$ terms a human-microbe hybrid, where the human genome and the microbiome collectively define a 'superorganism'. In the healthy human gut the composition of the microbiome is unique and consists of hundreds to thousands of bacterial species in largely four different phyla: Firmicutes, Bacteroidetes, Proteobacteria and Actinobacteria ${ }^{(86)}$ although they are not distributed uniformly in number, species or metabolic activity. Diet and age are known to influence the composition of the gut microbiome ${ }^{(87,88)}$. Although the intestinal tract is colonised by large numbers of commensal bacteria, intestinal infections and the translocation of bacterial proinflammatory antigens (for example, lipopolysaccharide and peptidoglycan) that can provoke NF-кBdependent immune responses are uncommon in healthy individuals. However, the development of IBD appears to be dependent on the presence of a commensal microbiota, as mice raised in germ-free environments fail to develop $\operatorname{IBD}^{(89)}$. While the classic interpretation of IBD pathogenesis is a loss of mucosal tolerance to proinflammatory bacteria, someone with IBD is more likely to contract an intestinal infection because of a weakened mucosal barrier, resulting from a defective immune defence system ${ }^{(25,90)}$.

An excessive immune response to bacteria inhabiting the intestinal lumen and their degradation products is a common feature of IBD. Despite recent progress in defining factors that exacerbate or ameliorate these diseases, their precise causes remain poorly defined ${ }^{(91)}$. Nevertheless, there is broad agreement that luminal microbes are of particular relevance in the development of these pathologies ${ }^{(6)}$. The composition of the microbiota is altered in IBD towards fewer anti-inflammatory and greater numbers of proinflammatory bacteria ${ }^{(92-94)}$. The treatment of IBD is often accompanied by substantial changes in the composition of intestinal microbiota and related immunoglobulins ${ }^{(95)}$. However, no single group of bacteria has been implicated to be uniquely causally related to these diseases ${ }^{(91)}$. It has been suggested that a toxin, such as $\mathrm{H}_{2} \mathrm{O}_{2}$ produced by bacteria, might play a significant role in provoking intestinal inflammation ${ }^{(91)}$. Although many studies have failed to link sulfate-reducing bacteria (SRB) and $\operatorname{IBD}^{(96-101)}$, it has been proposed that SRB can exacerbate IBD by generating hydrogen sulfide, as well as depleting the production of beneficial butyrate ${ }^{(102,103)}$. Although the work of Jia et $a l^{(91)}$ demonstrated some changes in the number of SRB in IBD patients pre- and post-treatment, their data were not unequivocal.

While there is little disagreement that patients suffering from IBD have antibodies against several microbes and microbial antigens $^{(104)}$, a number of researchers suggest that dysbiosis of the intestinal microbiome is a causal factor of inflammation in IBD patients, without reference to the genetic predisposition of IBD patients ${ }^{(6,9,10,89,105,106)}$. However, although commensal intraluminal microbiota are essential for the development and maintenance of IBD there is little evidence to support the hypothesis that intestinal microbiota are the single causal factor of the disease. Although the defence against these microbes is compromised in IBD it may be reasoned that this is due to a defective innate barrier where the production of $\alpha$-defensins is reduced in ileal $\mathrm{CD}$, that $\beta$-defensins are decreased in colonic $\mathrm{CD}$, and the mucus layer is deficient in $\mathrm{UC}^{(6)}$.

There is little evidence that the numbers of bacteria in the large intestine of human subjects with IBD are any different from those of normal subjects. However, a disequilibrium of inflammatory and non-inflammatory components of the intestinal microbiota (dysbioses) is associated with $\operatorname{IBD}^{(94,106-111)}$. Whether the changes in intestinal microbiota observed in IBD are simply a consequence of chronic inflammation and its treatment, or are necessary determinants of initiation and/or perpetuation of pathogenesis, is still open to question $^{(18)}$. Microbiological investigations have so far failed to identify consistent alterations of microbiota composition in IBD patients relative to healthy controls ${ }^{(111)}$. While the commensal microbiota are largely tolerated by the mucosa and ignored by the systemic immune systems of normal hosts $^{(112-114)}$, they are essential drivers of pathogenic mucosal and systemic inflammatory responses in genetically predisposed subjects ${ }^{(8,89,115,116)}$.

Such dysbiosis, widely reported in connection with $\mathrm{CD}^{(94,106-111)}$, is not solely the result of environmental effects, such as treatment history or diet. Complex interactions exist between the host genotype and the enteral microbial community ${ }^{(18)}$. Such interactions may arise as a consequence of direct genetic effects on microbial composition, perhaps through altered Paneth cell function ${ }^{(5,117,118)}$, or as a direct result of the pathogenic process. However, the question of whether dysbiosis contributes to $\mathrm{CD}$ pathogenesis or is an innocuous by-product remains to be established. Furthermore, how dysfunction or inflammation of the mucosal barrier can lead to dysbiosis is also unclear. However, other than in exceptional cases, it is unlikely that disease-associated dysbioses will satisfy all of the criteria that have been proposed to prove causality ${ }^{(119-121)}$. 
In a study of forty twin pairs focusing on disease incidence in genetically matched individuals that were concordant or discordant for either CD or UC, it was demonstrated that the microbiota of $\mathrm{CD}$ patients differed from those of healthy individuals, whereas the microbiota of patients with UC was similar to healthy controls ${ }^{(107)}$. Also the microbial profiles of patients with $\mathrm{CD}$, predominantly affecting the ileum, were different to those where the disease affected the colon. Although other studies have shown that the microbial profile of IBD patients differs in inflamed and non-inflamed states ${ }^{(122-124)}$, the faecal microbiota cannot be differentiated between patients with the active disease and those in remission ${ }^{(107)}$. In terms of microbial profile the disease phenotype was a more significant factor than genotype. Although significant differences in the microbial profile between inflamed and non-inflamed mucosal biopsy sites have been demonstrated, such differences varied so greatly between individuals that no obvious bacterial signature could be positively associated with the inflamed intestine $^{(124)}$. Although a dysbiosis is observed in IBD patients, relative to healthy controls, it may result from a disturbed intestinal environment rather than be the direct cause of disease. The complex mutualistic interaction between the microbiota and the host suggests that the relationship is bi-directional ${ }^{(125)}$ and that any observed inflammatory changes may be secondary to, rather than causative of, the disease process; this is a factor that must be considered in future studies ${ }^{(126)}$

It has previously been reported that a reduced abundance of Faecalibacterium prausnitzii, a bacterium thought to exert antiinflammatory effects ${ }^{(127)}$, is common in ileal CD patients ${ }^{(108,128)}$. However, F. prausnitzii only represents one of many core members of the microbiota that are less abundant in this disease phenotype. This has led to the suggestion that the oral replenishment of Roseburia, Alistipes, Collinsella and members of the Ruminococcaceae family may be beneficial ${ }^{(107)}$.

In humans there are at least eighteen mucin-type glycoproteins; however, mucin 2 (MUC2) is the predominant component of the mucin layer in both the small and large intestines $^{(129)}$. When comparing the thinning of the mucus layer in patients suffering from IBD with healthy controls there is evidence that Streptococcus is associated with CD (80\% of all bacteria) and that Lactobacillus is associated with UC (90\% of all bacteria) ${ }^{(130,131)}$. In a study by Joossens et $a l^{(132)}$ a faecal microbiota dysbiosis was identified in patients with CD that was characterised by a decreased presence of butyrate-producing bacteria in conjunction with mucin degradation; although the patients' relatives possessed similarly enhanced mucin degradation they did not share the depleted butyrate-producing bacteria.

As the mucosal barrier is the primary defence of the host against intestinal bacteria the shift from normobiosis observed in relatives of $\mathrm{CD}$ patients to the dysbiosis seen in $\mathrm{CD}$ patients might be an intermediate step towards CD and diseaseassociated dysbioses ${ }^{(132)}$. Although Joossens et al. ${ }^{(132)}$ did not study the overall butyrate-producing or mucin degradation capacity of the microbiota in this cohort, there was a functional overlap between dysbiosis in patients with $\mathrm{CD}$ and their unaffected relatives at risk. Quigley emphasises the importance of this study suggesting that it indicates a role of the microbiota in $\mathrm{CD}$ that is independent of the genetic background and diet, features that the $\mathrm{CD}$ patients would have shared with their unaffected relatives ${ }^{(125)}$. However, Quigley fails to mention the finding of Joossens et al. ${ }^{(132)}$ that the CD patients exhibited mucin degradation, a fact that weakens the argument that the microbiota in CD are independent of the genetic background and diet.

\section{The immune system}

Epithelial innate immunity includes pattern recognition receptors on the intestinal surfaces such as Toll-like receptors and nucleotide-binding oligomerisation domain (NOD)containing molecules. Recognition of bacteria by the vertebrate innate immune systems relies upon the detection of invariant molecules by specialised receptors. The view is now emerging that activation of both Toll-like receptors and NOD by different bacterial agonists is important in an inflammatory response $\mathrm{e}^{(133)}$. It appears that NOD1 and NOD2 receptors detect the peptidoglycan components of bacterial cell walls, and the nucleotide-binding domain, leucine-rich (NLR) proteins ipaf and Naip detect bacterial flagellin ${ }^{(134,135)}$. NOD1 specifically senses diaminopimelic acid-containing muramyl peptides ${ }^{(136,137)}$ and NOD2 detects muramyl dipeptide $(\mathrm{MDP})^{(138,139)}$, a motif found in almost all bacteria. Nod1 and Nod2 mutations have been associated with IBD in human subjects ${ }^{(140)}$, with Nod 2 being identified as the first susceptibility gene for $\mathrm{CD}^{(141,142)}$. It is hypothesised that any impairment to NOD2 function in innate immune responses to bacterial peptides, such as a dysfunctional PepT1 peptide transporter, may lead to defective sensing of bacterial proinflammatory peptides, abnormal bacterial survival and chronic inflammation of the intestinal mucosa ${ }^{(7)}$. The question of whether a defective PepT1 mechanism is a causative factor for the disease pathogenesis or severity of the IBD has yet to be determined ${ }^{(7)}$.

Constitutive and inducible antimicrobial peptides such as defensins and cathelicidins interact with secreted mucins and play an important role in intestinal defence ${ }^{(143,144)}$. Antimicrobial peptides, predominantly the defensins in mammals, possess a broad spectrum of antimicrobial activity. Antimicrobial peptides are hydrophobic peptides possessing positively charged domains that can interact with and disrupt cell membranes causing cell lysis, which leads to the efflux of ions and nutrients. In the small intestine, the most abundant constitutive defensins are the $\alpha$-defensins HD5 and HD6 found in the Paneth cells. Following stimulation of the pattern recognition receptors by bacterial products (for example, lipopolysaccharide, which activates Toll-like receptor-4, and MDP, which activates NOD2) ${ }^{(145)}$, defensins are released into the lumen. In comparison with vertebrate cell membranes, bacterial cells possess high concentrations of negatively charged phospholipids, which defensins selectively and preferentially bind to ${ }^{(146)}$. Together with antimicrobial lysozymes, Paneth cells are key to intestinal defence.

Most dietary protein is completely digested and absorbed as amino acids, dipeptides or tripeptides. However, some proteins are resistant to both the acidic $\mathrm{pH}$ of the stomach and enzyme proteolysis $^{(147)}$, such that large immunogenic peptides or intact 
proteins may reach the small intestine ${ }^{(148)}$. For example, $\beta$-lactoglobulin, a major bovine milk allergen, and gluten/ gliadins, a major factor underlying $\mathrm{CeD}$, are both partially resistant to digestive enzymes ${ }^{(28)}$. The ineffective digestion of gliadins which are high in proline content produce large irreducible immunogenic peptides that may activate the lamina propria $\mathrm{CD}^{+} \mathrm{T}$ cells in coeliac patients ${ }^{(149,150)}$. The risk of developing food allergies from incomplete protein digestion has been reported in mice given antiulcer medication known to impair protein digestion where even low doses of ovalbumin resulted in the development of IgE-mediated food allergy ${ }^{(151)}$. Such observations indicate that immunogenic proteins and peptides present in the lumen may serve as potential candidates for intestinal absorption and immune stimulation ${ }^{(28)}$.

Intestinal alkaline phosphatase (IAP) is expressed throughout the gastrointestinal tract and has an essential role in intestinal homeostasis through interactions with the microbiota resident in the gut ${ }^{(152)}$. IAP appears to have four major interactions in the gut: (a) the dephosphorylation of toxic pro-inflammatory microbial ligands such the lipopolysaccharides, components of the cell wall of Gram-negative bacteria, the presence of which in the blood can stimulate a strong inflammatory response; (b) the regulation of bicarbonate secretion and increasing the $\mathrm{pH}$ distal to the stomach; (c) modulation of long-chain fatty acid absorption; and (d) the regulation of the microbial ecosystem within the gut by forming a complex relationship between microbiota, diet and the intestinal mucosal surface, and the translocation of microbes across the gut wall $^{(152,153)}$. IAP also dephosphorylates other pro-inflammatory ligands released from damaged cells such as extracellular nucleotides, for example, ATP. The detoxification of such ligands is essential in the prevention of inflammatory conditions such as IBD. IAP is reported as having a protective effect by ameliorating inflammation from increased permeability of the intestinal endothelia that results from vascular endothelial growth factor affecting the pericellular TJ. Such abnormal intestinal permeability can be partially reduced by IAP downregulating vascular endothelial growth factor expression and regulating specific TJ proteins for example, claudin- $2^{(154)}$. Compared with normal subjects, epithelial IAP mRNA expression is reduced in patients with $\mathrm{UC}$ and $\mathrm{CD}^{(155)}$ and is especially marked in severe cases of $\mathrm{CeD}^{(156)}$. Animal studies have shown that orally administered IAP may reduce inflammation by down-regulating the immune response, specifically reducing pro-inflammatory cytokines, for example, TNF- $\alpha^{(152,157)}$. In an uncontrolled trial by Lukas et al. ${ }^{(158)}$, IAP was administered intraduodenally daily over a period of $7 \mathrm{~d}$ to patients with UC and was associated with short-term improvement in disease activity scores and clinical effects. The gastrointestinal administration of IAP appears to ameliorate both gut inflammation and favours intestinal tissue regeneration, whereas enteral and systemic administration of IAP attenuates systemic inflammation only ${ }^{(153)}$.

\section{Genetic disruption}

IBD is a multigenic disease where an increased number of inherited risk alleles is associated with an increased risk of developing the disease, earlier onset and greater severity (for example, fibrostenotic or fistulising symptoms and/or the necessity for surgical intervention $)^{(159,160)}$. However, genetic susceptibility does not necessitate the development of the disease, as studies with monozygous twins discordant for IBD suggest that diverse environmental interactions (for example, diet and gastrointestinal tract microbiome) also play a role in the development of this disease ${ }^{(107,108,161)}$. Using ordinal regression analysis, Weersma et $a l .{ }^{(159)}$ reported that individuals with six CD-associated risk alleles (OR 7.56) were unlikely to develop the condition whereas individuals with seven risk alleles (OR 25.6) were much more likely to develop CD. The genetic associations with IBD have been extensively reviewed by a number of researchers ${ }^{(162-169)}$. Genome-wide association studies have resulted in the rapid discovery of susceptibility genes with over 163 IBD genes associated with these diseases $^{(170-172)}$. Model-selection analysis has indicated that 110 of the 163 susceptibility loci are associated with both CD and UC, with thirty being specific to CD and twenty-three specific to $\mathrm{UC}^{(171)}$. More recently thirty-six loci specific to $\mathrm{CD}^{(173)}$ and 100 specific to UC have been reported ${ }^{(172)}$. These loci encode genes which are involved in a number of homeostatic systems, the disruption of which provide a mechanistic description of IBD. Dysfunctional genes that are implicated in epithelial barrier function, bacterial recognition and adaptive immune response are given Table 1 .

Advanced genomic techniques have identified other loci and polymorphisms that are associated with IBD and highlight other cellular pathways that may contribute to the onset or progression of the disease ${ }^{(174)}$. A further sixteen genes and loci

Table 1. Dysfunctional genes implicated in epithelial barrier function, bacterial recognition and adaptive immune response*

\begin{tabular}{lll}
\hline & Crohn's disease & Ulcerative colitis \\
\hline Epithelial barrier function & IBD5, DLG5, ITLN1, XBP1 & MDR1, MALB1, CDH1, HNF4A \\
Bacterial recognition & NOD1, NOD2, CARD9, TLR4, ATG16L1, IRGM, LRRK2 & IL23R, JAK2, STAT3, HLA region, IL10, MST1 \\
Adaptive immune response & IL23R, JAK2, STAT3, HLA region, IL10, MST1, PTPN2 & L
\end{tabular}

IBD5, inflammatory bowel disease 5; DLG5, drosophila discs large homolog; ITLN1, intelectin-1; XBP1, X-box binding protein 1; MDR1, multidrug resistance protein 1; MALB1, Mal region B mutants; $C D H 1$, cadherin 1; HNF4A, hepatocyte nuclear factor $4 \mathrm{a}$; NOD1 and 2, nucleotide-binding oligomerisation domain; $C A R D 9$, caspase recruitment domaincontaining protein 9; TLR4, Toll-like receptor 4; ATG16L1, autophagy-related protein 16-1; IRGM, immunity-related GTPase family M protein; LRRK2, leucine-rich repeat kinase 2; IL23R, IL23 receptor; JAK2, Janus kinase 2; STAT3, signal transducer and activator of transcription 3; HLA, human leucocyte antigen; MST1, macrophage stimulating 1; PTPN2, protein tyrosine phosphatase, non-receptor type 2.

* An additional sixteen genes and loci are implicated in inflammatory bowel disease after Graham \& Xavier ${ }^{(164)}$ : RNF186 (ring finger protein 186); SP110 (nuclear body protein 110); SP140 (nuclear body protein 140); MST1 (macrophage stimulating 1 (hepatocyte growth factor-like)); FUT2 (fucosyltransferase); SLC22A4 (solute carrier family); GSDMB (gasdermin B); ORMDL3 (orosomucoid like 3); TNFAIP3 (TNFa-induced protein 3); SLC6A7 (solute carrier family); IL10RA (IL10 receptor a); IL18RAP (IL18 receptor accessory protein); MUC19 (mucin 19); CUL2 (cullin 2); PTPN22 (protein tyrosine phosphatase, non-receptor type 22); C1orf106 (chromosome 1 open reading frame 106). 
implicated in IBD suggest connections between cellular metabolism, inflammation and mucosal microbial communities (see notes for Table 1$)^{(164)}$. A comprehensive review of SNP with either susceptibility or protective effects in IBD has recently been published $^{(165)}$. It appears there is significant overlap in genes associated with autoimmune and autoinflammatory diseases that indicate common immunological mechanisms and unique disease-specific pathways which lead to the complex pathophysiology of $\mathrm{IBD}^{(164)}$. A number of the susceptibility genes identified with IBD (for example, ATG16L1) are common variants with high prevalence in the healthy population ${ }^{(159)}$. Indeed many of the SNP implicated in IBD by genome-wide association studies are not independently causative of the disease phenotype; they exist as linked disequilibrium with as yet to be discovered variants that are functional ${ }^{(164)}$. In the future, genetic screening for IBD-related SNP, combined with an assessment of the intestinal microbiome and other environmental factors (for example, diet), might allow clinicians to identify patients at risk of IBD and improve differential diagnosis and optimise treatment efficacy of the disease ${ }^{(165,175)}$.

Interestingly Hu et al. ${ }^{(176)}$ generated mice in which the PepT1 gene was disrupted by the insertion of a lac $Z$ reporter gene under the control of the endogenous PepT1 promoter. Although the Pept1-null mice lacked expression of PepT1 protein in the intestine and kidney tissues in which this peptide transporter is normally expressed, the Pept1-deficient mice were found to be viable, fertile, grew to normal size and weight, and were without any obvious abnormalities ${ }^{(176)}$.

\section{Other environmental factors}

With the sudden emergence and dramatic increase in IBD during the last century ${ }^{(177)}$, a variety of environmental factors has been implicated with the onset of IBD, including: food storage in refrigerators, smoking, the use of non-steroidal anti-inflammatory drugs, and infections ${ }^{(178,179)}$. Diet and food additives have long been suspected as major factors in IBD pathogenesis ${ }^{(7)}$ and in this context two new fields of study have emerged: nutrigenetics, which recognises the effect of genetic variation on nutrient requirements, and nutrigenomics, which describes the impact of nutrient regulation of gene expression ${ }^{(162)}$. Although Qin ${ }^{(161)}$ suggests a multitude of possible dietary factors affecting IBD, he singles out saccharin and/or sucralose to be a key causative factor in the disease. Proposing a unified hypothesis regarding the aetiology for IBD, Qin suggests that saccharin inhibits both the activity of $\beta$-glucuronidase itself as well as the growth of $\beta$-glucuronidase-positive bacteria in the gastrointestinal tract which are necessary for the deconjugation of biliary bilirubin ${ }^{(180)}$, that in turn leads to damage of the protective mucus layer and the underlying gut tissue by the poorly inactivated digestive proteases $^{(181)}$ (the bacteria-protease-mucus-barrier hypothesis) ${ }^{(161)}$.

\section{Peptide permeability}

\section{Peptide transporters}

The principal transporter for the absorption of $\mathrm{di}^{-}$and tripeptides arising from the digestion of both exogenous and endogenous proteins in the intestinal lumen is the highcapacity, low-affinity PepT1 protein ${ }^{(26)}$. Peptide transporters are integral membrane proteins that mediate the cellular uptake of di- and tripeptides. In vertebrates there are two peptide transporter proteins: PepT1 expressed predominantly in brush-border membranes of the small intestine and PepT2 in the kidney and lung. Although PepT1 is highly expressed in the small intestine ${ }^{(182)}$ there is little or no expression in the healthy colon $^{(183)}$. These transport proteins operate as electrogenic proton/peptide symporters with a broad substrate specificity, possibly transporting 400 dipeptides and 8000 tripeptides composed of $\mathrm{L}-\alpha$ amino acids $^{(184)}$, but not free amino acids or peptides with more than three amino acid residues ${ }^{(185,186)}$. The electrochemical gradient across the apical enterocyte membrane is dependent upon the Na-proton exchanger NHE3 and allows the absorption of di- and tripeptides against a concentration gradient, enabling higher intracellular than extracellular peptide concentrations ${ }^{(187,188)}$.

Transport is enantio-selective and involves a variable proton-to-substrate stoichiometry for the uptake of neutral and mono- or polyvalently charged peptides. The peptide transporter proteins can also transport many therapeutic drugs (for example, $\beta$-lactam antibiotics, selected angiotensin-converting enzyme inhibitors, and peptidase inhibitors) and thereby determine their bioavailability and pharmacokinetics ${ }^{(184)}$. In addition, PepT1 has an important role in the innate immune response to bacteria by mediating the transepithelial transport of bacterial antigens ${ }^{(65)}$. Microbial peptides imported by PepT1, for example MDP, induce NOD2-dependent activation of the $\mathrm{NF}-\kappa \mathrm{B}$ pathway ${ }^{(7)}$ with submucosal macrophages that in turn release proinflammatory cytokines, for example, IL- 8 and the monocyte chemoattractant protein-1 (MCP-1 $)^{(189,190)}$. PepT1 polymorphisms in the SLC15A1 gene have been associated with IBD $^{(191)}$ and NOD2 polymorphisms with $\mathrm{CD}^{(190)}$. The clinical relevance of intestinal uptake in disease has recently been reviewed by Freeman ${ }^{(192)}$.

Despite the comprehensive analysis of the structure and functions of PepT1, with many hundreds of publications over the last 40 years, its overall importance in amino acid absorption from the gastrointestinal tract is still largely unknown ${ }^{(193)}$. Using mice lacking PepT1 $\left(\right.$ Pept $1^{-/}$) the extent that PepT1 deletion is compensated for by changes in expression and function of the amino acid transporters in intestinal epithelial cells and the role of the transporter in amino acid absorption and metabolism have been characterised ${ }^{(193)}$. The intragastric administration of ${ }^{15} \mathrm{~N}$-labelled proteins and the concomitant analysis of plasma and tissue amino acid levels have indicated that the role of PepT1 in the overall intestinal amino acid absorption is negligible when low amounts of protein are ingested. However, under conditions of a high protein load reaching the intestine, the maximum rate of hydrolysis in the lumen or at the brush-border membrane may be reached, leading to di- and tripeptides becoming available for PepT1 transport ${ }^{(193)}$. Nassl et al. ${ }^{(193)}$ suggested that when a highprotein diet is administered to Pept $1^{-/}$mice it may induce changes in body amino acid homeostasis that resemble a state of amino acid imbalance, with amino acids that are related to the urea cycle being over-represented. This is suggestive of an altered hepatic detoxification capacity in animals deficient in PepT1. 
Not all researchers share the same view; for example, the enteropathogenic $E$. coli (EPEC), a food-borne pathogen implicated in the pathophysiology of infantile diarrhoea ${ }^{(194)}$, may also induce PepT1 expression in colonocytes ${ }^{(195)}$. Nguyen et al. ${ }^{(195)}$ demonstrated that: EPEC transcriptionally induces functional PepT1 expression in the lipid rafts (LR) of colonocytes; that it induces PepT1 expression by intimately attaching to host cell membranes through LR; that the transcription factor $\mathrm{Cdx} 2$ is crucial for EPEC-induced PepT1 expression; and that PepT1 which are associated with LR have a role in bacterial-epithelial interaction and bacteria-induced intestinal inflammation. It is proposed that EPEC is a causal factor of human colonic PepT1 expression, activating signalling molecules within the LRs, resulting from changes in conformation and/or composition of LR, and consequently reducing the binding affinity of EPEC for LR. PepT1 appears to attenuate EPEC-triggered proinflammatory responses in intestinal epithelial cells, and therefore colonic PepT1 expression might be a host protective mechanism that modulates bacterial-epithelial interaction and inflammatory responses to pathogens ${ }^{(195)}$, a finding that is in line with that of other researchers ${ }^{(26,196-199)}$.

Apically expressed colonic PepT1 may be a host defence mechanism via its ability to modulate bacterial-epithelial interactions and colonic inflammation ${ }^{(26)}$. Colonic PepT1 expressed in IBD may absorb small proinflammatory peptides derived from bacterial peptidoglycans (for example, $\mathrm{N}$-formylmethionylleucyl-phenylalanine $(\mathrm{fMLP})^{(196)}, \mathrm{MDP}^{(197)}$ and L-Ala- $\gamma$-D-Glu-meso-diaminopimelic acid (Tri-DAP) ${ }^{(198)}$ ) that interact with NOD-like receptors and determine the activation level of inflammatory pathways such as the NF-кB and $\mathrm{MAPK}^{(198)}$. These pathways lead to proinflammatory cytokine/chemokine production and the subsequent migration of neutrophils into regions of inflammation and bacterial infection $^{(26,199)}$.

Dalmasso et al. ${ }^{(11)}$ used Tri-DAP to induce inflammation in human colonic HT29-Cl.19A cells. Similar to fMLP and MDP, Tri-DAP is a natural peptide released during peptidoglycan degradation of Gram-negative bacteria, a bacterial tripeptide that may pass through the PepT1 transporter. Although it is still unclear if the peptide induces PepT1 expression in colonocytes, this suggests that bacterial products might induce or regulate colonic PepT1 expression ${ }^{(200)}$, and that once PepT1 is expressed in the colon in IBD, then PepT1 could then be involved in the transport of bacterial peptides that aggravate inflammation. However, the studies of Dalmasso et al. ${ }^{(11)}$ did indicate that colonic epithelia only respond to peptidoglycan motifs such as Tri-DAP when such products are present in the cytosol and most importantly that colonocytes fail to transport Tri-DAP or are inert to Tri-DAP under normal physiological conditions when PepT1 is not expressed in the colon.

Although the peptide/histidine transporters PhT1 and PhT2 have been found in the villous epithelia of the human small intestine $^{(201)}$, their relevance in the absorption of peptides and peptidomimetics has not been established ${ }^{(26)}$. However, it appears that neither of these transporters is involved in the absorption of the proinflammatory peptide fMLP ${ }^{(202)}$.

The multidrug resistance 1 gene (MDR1), which encodes for the membrane-bound efflux transporter P-glycoprotein
170 (P-gp), has been associated with IBD and thought to protect the intestinal epithelia from the uptake of endogenous and exogenous toxins by transporting drugs and xenobiotics into the lumen ${ }^{(7,203)}$. Although several SNP of this gene have been reported, its relevance to the pathogenesis of IBD varies across ethnic groups ${ }^{(204-207)}$.

\section{Epithelial barrier dysfunction, peptides and Crohn's disease}

The studies of Cadwell et $a l .{ }^{(5)}$ have demonstrated that a common enteric viral pathogen, norovirus, can induce a mutation in the CD susceptibility gene $\operatorname{Atg} 16 L 1$, producing intestinal pathologies in mice. These pathologies, activated by virus-plus-susceptibility gene interaction that mimic aspects of $\mathrm{CD}$, were dependent on IFN- $\boldsymbol{\gamma}$ and TNF- $\alpha$, and were preventable by treatment with broad-spectrum antibiotics ${ }^{(5)}$. Sabbah et al. ${ }^{(208)}$ have demonstrated that NOD2 can also function as a cytoplasmic viral pattern recognition receptor that can sense viral single-stranded RNA and activate IFN production. As a result it has been suggested that the CD-associated gene NOD2 may recognise viral RNA in addition to bacterial peptidoglycan and raises the possibility that a viral infection can interact with CD susceptibility genes ${ }^{(5)}$. Both Garrett et al. ${ }^{(209)}$ and Cadwell et $a l^{(5)}$ give clear insight into the complex interaction between gene and pathogen, which individually may display only poor association with disease incidence and severity. In animal models with induced pathology, reproducing the full disease may require combinations of specific alleles of multiple genes with certain environmental agents. Not all patients with CD present with identical symptoms or pathologies; the disease varies with time and also with age, sex, ethnicity, temporal trends and geographical distributions ${ }^{(177,210)}$. Some therapeutic interventions may alleviate symptoms of one patient but not in others ${ }^{(5)}$. Such complex IBD diseases may represent a combinatorial confluence of pathological responses, each with overlapping but non-identical genetic and environmental causes and therefore require different therapeutic responses ${ }^{(5)}$.

In $\mathrm{CD}$, a transcription factor-4-mediated defect in Paneth cell differentiation has been linked to a specific absence of the $\alpha$-defensins, especially in patients with $\operatorname{Nod} 2$ mutations ${ }^{(6)}$. Consequently, the deficient mucosal barrier allows luminal microbes to invade the mucosa and trigger a secondary inflammatory response $\mathrm{e}^{(25)}$

The up-regulated expression of PepT1 in patients with IBD $^{(211)}$ and NOD2 mutations associated with $\mathrm{CD}^{(138)}$ may result from defective sensing of bacterial peptidoglycan-derived peptides such as MDP (a NOD2 agonist) ${ }^{(183)}$. As a result of NOD2 mutations, which result in a NOD2 deficiency, a loss of microbial surveillance and the unmonitored import of microbial proinflammatory peptides may be caused that contribute to the onset of CD.

The expression of PepT1 in the colon of patients with UC or $\mathrm{CD}$ may be a response to the absorption of chemotactic bacterial di- and tripeptides that cause an aggravated inflammation/ immune response ${ }^{(10,26)}$. The expression of PepT1 in human colonocytes has also been linked to leptin, an adipocytesecreted hormone. High concentrations of leptin were found in 
inflamed colonic mucosa which in turn triggered the colonic expression of PepT1 via the cAMP response element-binding (CREB) and Cdx2 transcription factors. Such increased expression of colonic PepT1 may thus enhance the uptake of the small bacterial di- and tripeptides that perpetuate intestinal inflammation. Such findings may provide important new insights into the mechanisms of intestinal inflammation and its treatment ${ }^{(212)}$.

Although the mechanism of colonic PepT1 expression in IBD remains unknown, it has been suggested that its expression is most probably induced at a transcriptional level, where specific transcriptional regulation by signalling pathway(s) may be activated $^{(195,211,213,214)}$. However, Vavricka et al. ${ }^{(189)}$ demonstrated both in vitro (in human colonic $\mathrm{CacO} 2 / \mathrm{bbe}$ monolayers) and in vivo (in mouse intestine), that TNF- $\alpha$ and IFN- $\gamma$ increased the activity and the total and apical membrane protein expression of PepT1 protein in a concentration- and time-dependent fashion. As no changes in PepT1 mRNA were observed, it may be concluded that the increased PepT1 activity and expression were post-transcriptionally regulated ${ }^{(189)}$. Current research into the expression of PepT1 transporters in the colon of patients with some form of IBD suggests that the presence of PepT1 in the colon is due to the bacterial load of the colon being higher than that of the ileum, and that such a high bacterial load creates a concomitantly high luminal concentration of bacterial peptides, which PepT1 transporters absorb, thus stimulating an exaggerated proinflammatory immune response.

It has also been suggested that PepT1 expression is normally restricted to the small intestine because the concentrations of bacterial di- and tripeptides are much lower in the small intestine than in the colon and that the human small intestine contains only low numbers of prokaryotes ${ }^{(9)}$. However, this statement can be challenged in light of the evidence that the numbers of bacteria present in the distal ileum may be as high as $10 \% / \mathrm{ml}$ of digesta ${ }^{(215)}$. Although less than the densities reported by Whitman et al. for the large intestine $\left(10^{11}-10^{12} / \mathrm{ml}\right.$ digesta $^{(216)}$ ), they are in sufficient numbers that the presence of substantial quantities of bacterial di- and tripeptides in the ileum cannot be discounted, and are not evidential as to the lack of inflammation in the healthy human small intestine. Ingersol et $a l .{ }^{(9)}$ suggest that the presence of colonic PepT1 transporters is solely due to the higher numbers of bacteria in the large bowel as the profile of PepT1 expression along the normal human digestive tract is such that bacterial peptides have little access to PepT1 and minimises the intracellular uptake of bacterial peptides. As PepT1 expression is altered in patients with IBD and commensal bacteria colonising the human colon produce significant amounts of proinflammatory di- and tripeptides, the transport of the peptides by PepT1 may lead to an increased intracellular accumulation of prokaryotic peptides that trigger downstream proinflammatory effects ${ }^{(9)}$.

\section{Epithelial barrier dysfunction, peptides and ulcerative colitis}

In experiments with conventionally raised $\mathrm{T}_{-} \mathrm{bet}^{-/-} \times \mathrm{Rag}^{-/-}$ knockout mice lacking an adaptive immune system, the loss of the transcription factor T-bet results in a spontaneous and highly penetrant colitis that shares histological features with
UC in humans ${ }^{(217)}$. T-bet $^{-1} \times$ Rag $^{-/-} \mathrm{UC}$ (TRUC) is associated with altered colonic barrier function, elevated TNF- $\alpha$ levels and dysfunctional dendritic cells. Both the T-bet-deficient genetic background and the microbiota are required for disease initiation $^{(217)}$. Once the disease is established, the microbiota from the afflicted mice are vertically transmissible and cause intestinal inflammation in wild-type mice. TRUC is transmissible to wild-type hosts when they are cross-fostered or co-housed with TRUC mice. In a later paper, Garrett et al. ${ }^{(209)}$ demonstrated that the presence of Proteus mirabilis and Klebsiella pneumoniae contributes to disease pathogenesis of colitis in TRUC mice and that TRUC-derived strains, in conjunction with an endogenous microbial community, incite colitis in wild-type mice ${ }^{(209)}$. Their results may provide mechanistic insights about how intestinal microbial communities, working in concert with specific colitogenic agents, contribute to the initiation and perpetuation of IBD in susceptible human hosts, and provide the foundation for proof-of-concept tests of preventative or therapeutic measures ${ }^{(209)}$.

Dietary protein is, to the host, foreign protein that may contain peptides that would trigger an immune response if exposed to the immune system in the enterocyte/lamina propria/ bloodstream. The bacterial di- and tripeptides fMLP and MDP have been found to elicit an immune response; therefore it is probably safe to assume that there are other hydrolysis-resistant dietary peptides which could also elicit a similar response. Therefore any leakage of the apical/basolateral membranes would also elicit a similar response that results in inflammation. A high intake of dairy products or low dietary fibre intake has been reported to be associated with the relapse of patients with $\mathrm{UC}^{(218-221)}$. However, more recently Jowett et al. ${ }^{(14)}$ detected no association between the intake of milk or dairy products and relapse of UC, neither did they find any protective effect from increased dietary fibre. However, they did find that the consumption of meat (particularly red meat and processed meat), protein, and alcohol were linked to increased relapse in patients with $\mathrm{UC}^{(14)}$. Speculation that the high sulfur or sulfate compounds in many of these foods was the trigger associated with the relapse of UC has led to a number of studies ${ }^{(14,222)}$ not least of which were those of Marquet et $a l^{(103)}$, Shatalin et $a .^{(102)}$ and Jia et $a l .^{(91)}$ that highlighted the toxicity of hydrogen sulfide, possibly mediated through the impaired utilisation of butyrate in colonocytes ${ }^{(223)}$. Carbohydrates have also been reported to result in colonic inflammation ${ }^{(224)}$ and promote UC in some individuals ${ }^{(22)}$. Although enteral feeding to control dietary intake has been effective in the treatment of $\mathrm{CD}$, it is ineffective in $\mathrm{UC}^{(225)}$

Large numbers of peptides have been isolated from both milk $^{(226-228)}$ and meat ${ }^{(229-232)}$ and the possible existence of small proinflammatory peptides similar to the previously identified proinflammatory bacterial peptides cannot be excluded. Recently, Chatterton et al. ${ }^{(233)}$ reviewed the anti-inflammatory mechanisms of milk proteins that assist in the prevention of a severe form of intestinal inflammation known as necrotising enterocolitis which is associated with a high mortality in neonates. In this review, the authors commented that although raw human milk contains many anti-inflammatory proteins (for example, immunoglubulins 
that chelate bacterial and viral proinflammatory antigens), bovine milk may have much fewer anti-inflammatory components due to digestive proteolysis and pasteurisation $^{(233)}$. Various growth factors present in both human and bovine milk have been reported as having anti-inflammatory properties $^{(15,233)}$. Transforming growth factor- $\beta 1$ (TGF- $\beta 1$ ) was reported by Letterio et $a l^{(234)}$ to have anti-inflammatory properties, which were later attributed to the modulation of inflammatory responses ${ }^{(179)}$. TGF- $\beta$ regulates the differentiation of $\mathrm{T}$ helper 17 cells (Th17-cells) which maintain intestinal barrier integrity and produce the anti-inflammatory cytokine IL-10 ${ }^{(235)}$. Heparin-binding epidermal growth factor-like growth factor was found to attenuate bacterial binding to the intestinal $\operatorname{mucosa}^{(236)}$, repress the cytokine-induced activation of NF- $\mathrm{BB}$ and release of proinflammatory cytokines ${ }^{(237,238)}$.

The hypothesis that dietary proteins and their hydrolysates contain peptides that may affect mucin secretion has been studied by a number of researchers ${ }^{(239-242)}$. The casomorphins, a family of bioactive peptides derived from milk $\beta$-casein, are opioid agonists known to affect the secretion of mucin, a protective response that also stimulates the production of epidermal growth factor, that in turn promotes epithelial cell proliferation $^{(243)}$. The effect of various opioid-acting casomorphins on mucin secretion has been reported by a number of researchers ${ }^{(241,244)}$ who found that the intraluminal administration of $\beta$-casomorphin-7 provoked a $500 \%$ increase (over the controls) in the secretion of mucin. $\beta$-Casomorphin- 7 seems unique in this respect as little or no increase in mucin secretion was observed from any of the other opioid peptides tested. Milk-borne opioid receptor ligands have been extensively reviewed by Clare \& Swaisgood ${ }^{(245)}$. Zoghbi et al. ${ }^{(246)}$ reported that $\beta$-casomorphin-7 increased the expression of $r M u c 2$ and may contribute significantly to mucin production through a direct effect on intestinal goblet cells and the activation of $\mu$-opioid receptors. Because intestinal mucins are an integral part of epithelial barrier function, dietary supplements containing $\beta$-casomorphin-7 are worthy of investigation for their potential to improve intestinal protection in IBD.

Secretory mucin MUC2 is the predominant structural component of the mucus layer and is abundantly expressed by goblet cells in the colon ${ }^{(247,248)}$. MUC2 synthesis is decreased in both human and animal models of $\operatorname{IBD}^{(249,250)}$, and the expression of MUC2 is considered as a phenotypic marker, which can be inversely correlated with the severity of inflammation $^{(251)}$. Quantitative changes in mucin secretion occur in IBD that include structural changes in the glycoprotein core together with the sulfation and sialylation of the oligosaccharide residues. Such changes are associated with a dysfunctional mucous barrier ${ }^{(252)}$. In UC, defensin synthesis and activity are not disturbed, even in inflamed mucosa; however, deficiencies in the mucus layer of UC patients are indicative of defects in goblet cell differentiation. With a diminished mucus layer the secreted defensins in physiologically normal concentrations are not retained and this allows bacteria to pass through the epithelium and induce inflammation ${ }^{(6)}$. There is evidence that matrix metalloproteinases (MMP) are the predominant extracellular proteinases within the mucosa disorders such as IBD and peptic ulcer disease ${ }^{(253-255)}$. Both serum and tissue levels of
MMP-9, localised in the colonic mucosa ${ }^{(256)}$, are known to correlate with disease activity in $\mathrm{UC}^{(254,257,258)}$. Garg et al. ${ }^{(259)}$ demonstrated that MMP-9 modulates MUC2 expression by regulating goblet cell differentiation. Overexpression of MMP-9 inhibits goblet cell differentiation with a concomitant decrease in MUC2 mucin ${ }^{(260,261)}$. The aberrant expression of MMP-9, observed in inflammatory conditions, leads to the impaired differentiation and a consequent decrease in goblet cell function, known to be associated with increased susceptibility to bacterial infection/inflammation ${ }^{(259)}$. A target for future IBD therapies may be to strengthen the mucous barrier through the up-regulation/down-regulation of MUC genes, the manipulation of post-transcriptional processing, or targeting the mucin molecule itself ${ }^{(252)}$.

\section{Epithelial barrier dysfunction, peptides and coeliac disease}

$\mathrm{CeD}$ is a chronic immune-mediated disorder that primarily affects the mucosa of the small intestine. The condition is a food antigen-triggered autoimmune disorder that involves an immune response (both innate and adaptive) following exposure to dietary gluten-containing foods in genetically predisposed individuals. The pathogenesis of CeD involves a triad of predisposing genes, gluten and other environmental factors. The inception of CeD follows the deamination of gliadins, monomeric proteins contained in gluten, by tissue transglutaminase. Gliadin immunogenic fragments, resistant to endopeptidases, then bind to the chemokine CXCR3 present on the luminal surface of the enterocytes. Zonulin, one of the transmembrane proteins that regulate epithelial barrier permeability, may then be released from the TJ as a result of gliadin binding to CXCR3 ${ }^{(262)}$. The MyD88 adapter protein-dependent release of zonulin, highly expressed in $\mathrm{CeD}$, results in the disassembly of the TJ and a subsequent increase in intestinal permeability $^{(263)}$ and activation of antigen-presenting cells (for example, macrophages, dendritic cells and B cells). These cells in turn display the gliadin peptides and interact with gluten-specific $\mathrm{CD}^{+} \mathrm{T}$ cells in the lamina propria. $\mathrm{CD}^{+} \mathrm{T}$ cells release inflammatory cytokines (for example, IFN- $\gamma$ and IL-15) that facilitate the transformation of intraepithelial lymphocytes into cytotoxic $\mathrm{CD}^{+} \mathrm{T}$ cells that kill the intestinal epithelial cells. The cumulative effect of this inflammatory cascade is the manifestation of villous atrophy and crypt hyperplasia ${ }^{(264)}$. Inflammation of the intestinal epithelia consequent to the gliadin assault on the enterocytes may then exacerbate intestinal barrier dysfunction leading to the increased passage of antigens involved in the pathogenesis of CeD. In genetically predisposed individuals (those carrying the HLA-DQ2 or less commonly HLA-DQ8 haplotype) environmental factors, such as rotavirus infection, toxins or Fe-deficiency anaemia, are thought to initiate the development of $\mathrm{CeD}^{(28)}$. It is interesting to note that constitutive abnormalities in intestinal permeability are not the hallmarks of food allergy; increased epithelial permeability is more the consequence of immunological changes producing villous atrophy, rather than the cause of food sensitisation ${ }^{(265)}$. For example, significant increases in the trans-epithelial transport of horseradish peroxidase (about $44 \mathrm{kDa}$ ) are observed in children with active cows' milk allergy, which 
return to normal levels following a cows' milk-free diet $^{(28)}$. However, increases in epithelial permeability are the cause of a self-perpetuating cycle that maintains allergic inflammation ${ }^{(266)}$.

A number of non-dietary therapies are currently under investigation that target specific aspects of $\mathrm{CeD}$ pathogenesis including intraluminal agents, immunomodulators and vaccination $^{(267,268)}$. Larazotide acetate (AT-1001), a peptide derived from cholera toxin, is thought to regulate intestinal paracellular permeability by inhibiting the disassembly of intestinal TJ. However, current clinical trials with larazotide have not demonstrated any decrease in intestinal permeability in CeD patients taking the drug, although decreased tissue transglutaminase IgA levels and improved clinical symptoms were observed ${ }^{(269,270)}$. Other proposed treatments include: reduced gluten exposure by genetic modification of the cereal grains containing gluten ${ }^{(271,272)}$; or using co-polymeric binders of gluten ${ }^{(273)}$; pre-digestion of gluten before intestinal epithelial cell uptake using prolyl-endopeptidases ${ }^{(274,275)}$; transglutaminase inhibitors or the blockade of HLA-DQ2/DQ8 ${ }^{(276-278)}$; and immune tolerance induction ${ }^{(279,280)}$

\section{Peptide permeability: is it the cause or consequence of intestinal disorders?}

That intestinal barrier dysfunction is the primary cause of intestinal disorders, such as food allergy, CeD and IBD, involving the transformation of antigenic tolerance into antigenic sensitisation following the excessive absorption of antigens, is a longstanding hypothesis to explain the pathogenesis of these diseases ${ }^{(28)}$. However, in food allergy, constitutive abnormality in intestinal permeability is unrecorded, and permeability to horseradish peroxidase in infants with active bovine milk allergy returns to normal following treatment with a milk-free $\operatorname{diet}^{(281)}$. Infection might be the triggering factor in CeD where inflammation increases intestinal permeability to gliadin peptides and thus immune responses in susceptible individuals. Rotavirus infection is associated with a higher risk of $\mathrm{CeD}$ in early childhood $^{(282)}$. Increased permeability to intact gliadin peptides observed in active $\mathrm{CeD}^{(283)}$ ceases in most coeliac patients once treated with a gluten-free diet.

The hypothesis that a primary defect is the cause of intestinal barrier dysfunction in patients with IBD arises from observations of hyperpermeability in CD patients before phenotypic symptoms arise and an increased permeability in the healthy relatives of IBD patients ${ }^{(22)}$. A genetic susceptibility to CD has been indicated by genome-wide association studies where a number of distinct genomic loci are involved in the maintenance of epithelial barrier integrity ${ }^{(8,284)}$. Variants of the myosin IXB (myo 9B) gene, that codes for the myosin IX motor protein, have been associated with $\operatorname{IBD}^{(285,286)}$ and $\mathrm{CeD}^{(287)}$, and may suggest a primary defect in intestinal permeability in these diseases ${ }^{(28)}$. Foster \& Zheng ${ }^{(199)}$ demonstrated that the inflammatory cytokine IFN- $\gamma$ increases intestinal PepT1 expression, which in turn mediates the absorption of the proinflammatory bacterial peptide IMLP $^{(288)}$. They demonstrated that cephalexin inhibits fMLP transport across cultured intestinal monolayers, which partially attenuates polymorphonuclear leucocyte-induced intestinal hyperpermeability. From their data it may be concluded that the use of pharmacological PepT1 substrates such as cephalexin may represent a novel means of preserving intestinal barrier integrity ${ }^{(199)}$.

\section{Current therapy}

Steroids remain the conventional treatment in acute inflammation of $\mathrm{CD}^{(289)}$. The two main immunosuppressant drugs are azathioprine and methotrexate ${ }^{(290)}$. Unfortunately, current anti-inflammatory therapy remains unsatisfactory due to substantial side effects and uncontrolled relapses ${ }^{(25)}$. Treatment with antibiotics are only effective in limited situations probably due to the modification of commensal microbiota ${ }^{(25)}$. Probiotics can modify luminal microbiota to suppress pathogens by producing inhibitory substances including $\mathrm{H}_{2} \mathrm{O}_{2}$, organic acids and bacteriocins, substances which inhibit both the proliferation of pathogens, toxin production and bacterial metabolism ${ }^{(2)}$. Although the treatment of colitis in human patients with Lactobacillus plantarum has yet to be established, it has been reported to be effective in the treatment and prevention of colitis in $I l 10^{-/}$mice ${ }^{(12,185,291)}$ by modulating the apical junctional complex proteins and PepT1-mediated transepithelial transport ${ }^{(93)}$. Probiotic bacteria like E. coli Nissle 1917 can induce antimicrobial peptides ${ }^{(292,293)}$ mediated by a specific flagellin ${ }^{(294)}$. It has been shown to be as effective as mesalazine in maintaining remission in $\mathrm{UC}^{(295)}$ although its effectiveness is much lower in the treatment of CD.

Since the advent of anti-TNF- $\alpha$ agents in the mid-1990s the treatment of IBD has changed significantly. Potent antiinflammatory medications for the treatment of IBD have emerged. Infliximab has proved effective for the induction and maintenance of remission in CD and UC that leads to mucosal healing, the reduction of hospitalisations and surgeries, the closure of intestinal fistula and the improvement of patients' quality of life ${ }^{(296)}$. Infliximab is a chimeric anti-TNF- $\alpha$ antibody that binds to proinflammatory TNF- $\alpha$ and induces complement activation and the apoptosis of inflammatory cells ${ }^{(83)}$. However, the high cost of treatment and the uncertainty of long-term safety have led to limited clinical use. A number of toxicity issues related to anti-TNF- $\alpha$ therapies have been reported including cases of heart failure and mycobacterial infections with the possible development of autoimmune disease, lymphomas and neurological disorders ${ }^{(297-300)}$.

Many researchers report that although antibiotics and some probiotics may alleviate some of the symptoms of IBD they do not reduce inflammation completely ${ }^{(198,222,301-304)}$. Surely if the action of bacterial di- and tripeptides were the sole cause of inflammation, antibiotics would be expected to remove such inflammation completely. However, this is not the case and would indicate that bacterial di- and tripeptides are not the only cause of inflammation in IBD.

As PepT1 is up-regulated in IBD, and absorbs proinflammatory peptides such as fMLP (in UC) and is linked to NOD receptors, it is a worthy target for IBD therapeutics. Although a number of researchers have characterised novel high-affinity inhibitors for PepT1 and their use for the delivery of 
peptidomemitic drugs ${ }^{(305-308)}$, few have explored the application of PepT1 inhibitors in the treatment of IBD. However, a number of peptides have been identified as having PepT1mediated anti-inflammatory activity in animal models and these include Lys-Pro-Val ${ }^{(309)}$ and Lys-Pro-Tyr ${ }^{(310)}$ peptides and the peptidomemitic drug cephalexin ${ }^{(199)}$. In the future such enteral peptidomemitic drugs and nutritional oligopeptides may offer patients with IBD an alternative to conventional treatments.

IL-6, released by activated submucosal macrophages and $\mathrm{CD}^{+} \mathrm{T}$ cells, is a key factor in the uncontrolled inflammatory process of IBD and antibodies against this cytokine have shown promise in phase I and II clinical trials ${ }^{(311,312)}$. In view of the severe side effects associated with TNF- $\alpha$ therapy there is a need to identify alternative IBD therapeutic strategies that do not entirely block cytokine responses. The application of the blocking protein sgp130 selectively inhibits IL-6 trans-signalling without affecting signals mediated via membrane-bound IL-6R and Mitsuyama et al. ${ }^{(313)}$ have suggested that the use of this strategy in inflammatory disease will lead to fewer side effects.

Recently exclusive enteral nutrition (EEN) has been shown to be more effective than corticosteroids in achieving mucosal healing for paediatric CD sufferers ${ }^{(314)}$. Navas-López et al. $^{(314)}$ found that EEN administered for 6-8 weeks was effective in decreasing mucosal inflammation and inducing clinical remission. Although several studies have demonstrated the efficacy of EEN as a maintenance therapy, the long-term effectiveness of EEN has not been investigated fully. If EEN is an effective therapy for the maintenance of remission, it may reduce the use of steroids and immunosuppressive drugs together with reducing the serious adverse events associated with these medications ${ }^{(315)}$. In their study of the long-term administration of enteral aminosalicylates, Konno et al. ${ }^{(315)}$ reduced the rate of intestinal surgery in paediatric CD. However, there are conflicting views on the efficacy of EEN and concomitant infliximab therapy. While Hirai et al. ${ }^{(316)}$ found that cumulative remission was considerably higher in patients receiving EEN than a non-EEN control, Yamamoto et al. ${ }^{(317)}$ found similar remission rates for both groups. In response, Chiba et al. ${ }^{(318)}$ pointed out a number of flaws in the previous studies and showed that the efficacy of EEN during infliximab maintenance therapy is dependent upon when infliximab is first administered. They demonstrated that although there is little benefit for patients with short disease duration, there were substantial benefits for patients of long disease duration ${ }^{(318)}$. Research into the effectiveness of EEN therapy for maintaining remission in both child and adult CD sufferers requires long-term, multisite randomised controlled trials.

\section{Conclusion}

There can be little doubt that deleterious proinflammatory di- and tripeptides can cross the intestinal epithelia barrier in relatively small amounts (from a nutritional perspective) and produce an immune response that may result in inflammation. Furthermore, it can also be assumed that inflammation can induce further leakage of the intestinal epithelial barrier. Whereas the intestinal absorption of the bacterial peptides fMLP, MDP and Tri-DAP, via PepT1, cause an inflammatory response there is no reason to believe that these are the only small peptides that can be absorbed via the PepT1 transporter. Other food-borne di- and tripeptides may also resist acid hydrolysis and enzymic proteolysis, causing an immune response that leads to inflammation in IBD. Although a number of researchers have highlighted the potential of toxic foodderived peptides ${ }^{(319,320)}$, the incidence of IBD even in the antigen-poor Western societies is small in comparison with the number of healthy individuals exposed to the same food antigens and must be considered evidential that in normal healthy subjects the transport of both small di- and tripeptides and/or macromolecules is (other than in antigen sampling) below the threshold necessary to cause an inflammatory disease. Other than in disease states, digestive processes both effectively and efficiently degrade dietary proteins so that only a few intact molecules come into contact with antibody molecules and any resultant complexes are unlikely to be absorbed ${ }^{(321)}$.

The present review raises a number of questions that warrant further research. If the main cause of the IBD inflammation is faulty peptide transporters can these be inhibited or attenuated without any detrimental effects to the patients' nutritional uptake from the intestinal tract? The work of Hu et al. ${ }^{(176)}$ with mice devoid of a functional PepT1 transporter indicates that this may be the case. As $\beta$-casomorphin-7 is known to increase the secretion of mucin in the small intestine ${ }^{(241)}$, can this small peptide be utilised therapeutically to increase mucin protection in intestinal tissues denuded of mucins, such as in UC?

\section{Acknowledgements}

We would like to thank the Riddet Institute, a New Zealand Government-funded Centre of Research Excellence, for supporting this research.

There was no direct source of funding for this research.

The first draft of this manuscript was written by W. M. M.-W. and edited by P. J. M.

The authors report no conflicts of interest with this research.

\section{References}

1. Davies JM \& Abreu MT (2015) The innate immune system and inflammatory bowel disease. Scand J Gastroenterol 50, 24-33.

2. Khan MW, Kale AA, Bere P, et al. (2012) Microbes, intestinal inflammation and probiotics. Expert Rev Gastroenterol Hepatol 6, 81-94.

3. Wehkamp J, Schwind B, Herrlinger KR, et al. (2002) Innate immunity and colonic inflammation: enhanced expression of epithelial $\alpha$-defensins. Dig Dis Sci 47, 1349-1355.

4. Wehkamp J, Schmid M, Fellermann K, et al. (2005) Defensin deficiency, intestinal microbes, and the clinical phenotypes of Crohn's disease. J Leuk Biol 77, 460-465.

5. Cadwell K, Patel KK, Maloney NS, et al. (2010) Virus-plus-susceptibility gene interaction determines Crohn's disease gene Atg16L1 phenotypes in intestine. Cell 141, 1135-1145.

6. Gersemann M, Wehkamp J \& Stange EF (2012) Innate immune dysfunction in inflammatory bowel disease. J Intern Med 271, 421-428. 
7. Gruber L, Lichti P, Rath E, et al. (2012) Nutrigenomics and nutrigenetics in inflammatory bowel diseases. I Clin Gastroenterol 46, 735-747.

8. Xavier RJ \& Podolsky DK (2007) Unravelling the pathogenesis of inflammatory bowel disease. Nature 448, 427-434.

9. Ingersoll SA, Ayyadurai S, Charania MA, et al. (2012) The role and pathophysiological relevance of membrane transporter PepT1 in intestinal inflammation and inflammatory bowel disease. Am J Physiol Gastrointest Liver Physiol 302, G484-G492.

10. Charrier L \& Merlin D (2006) The oligopeptide transporter hPepT1: gateway to the innate immune response. Lab Invest 86, 538-546.

11. Dalmasso G, Nguyen HTT, Charrier-Hisamuddin L, et al. (2010) PepT1 mediates transport of the proinflammatory bacterial tripeptide 1-Ala- $\gamma$-d-Glu-meso-DAP in intestinal epithelial cells. Am J Physiol Gastrointest Liver Physiol 299, G687-G696.

12. de Medina FS, Daddaoua A, Requena P, et al. (2010) Session 9: Food ingredients, immunity and inflammation: animal and in vitro models. New insights into the immunological effects of food bioactive peptides in animal models of intestinal inflammation. Proc Nutr Soc 69, 454-462.

13. Ma K, Hu YJ \& Smith DE (2012) Influence of fed-fasted state on intestinal PEPT1 expression and in vivo pharmacokinetics of glycylsarcosine in wild-type and Pept1 knockout mice. Pharm Res 29, 535-545.

14. Jowett SL, Seal CJ, Phillips E, et al. (2003) Defining relapse of ulcerative colitis using a symptom-based activity index. Scand J Gastroenterol 38, 164-171.

15. Rutherfurd-Markwick KJ \& Moughan PJ (2005) Bioactive peptides derived from food. J AOAC Int 88, 955-966.

16. Jappar D, Hu YJ \& Smith DE (2011) Effect of dose escalation on the in vivo oral absorption and disposition of glycylsarcosine in wild-type and Pept1 knockout mice. Drug Metab Dispos 39, 2250-2257.

17. Nassl AM, Rubio-Aliaga I, Sailer M, et al. (2011) The intestinal peptide transporter PEPT1 is involved in food intake regulation in mice fed a high-protein diet. PLOS ONE 6, e26407.

18. Frank DN, Zhu W, Sartor RB, et al. (2011) Investigating the biological and clinical significance of human dysbioses. Trends Microbiol 19, 427-434.

19. Olaison G, Sjodahl R \& Tagesson C (1990) Abnormal intestinal permeability in Crohn's disease: a possible pathogenic factor. Scand J Gastroenterol 25, 321-328.

20. Hollander D (1992) The intestinal permeability barrier. A hypothesis as to its regulation and involvement in Crohn's disease. Scand J Gastroenterol 27, 721-726.

21. Soderholm JD, Peterson KH, Olaison G, et al. (1999) Epithelial permeability to proteins in the noninflamed ileum of Crohn's disease? Gastroenterology 117, 65-72.

22. Hollander D, Vadheim CM, Brettholz E, et al. (1986) Increased intestinal permeability in patients with Crohn's disease and their relatives: a possible etiologic factor. Ann Intern Med 105, 883-885.

23. Travis S \& Menzies I (1992) Intestinal permeability: functional assessment and significance. Clin Sci 82, 471-488.

24. Bjarnason I, Macpherson A \& Hollander D (1995) Intestinal permiability: an overview. Gastroenterology 108, 1566-1581.

25. Wehkamp J \& Stange EF (2010) Paneth's disease. J Crohns Colitis 4, 523-531.

26. Smith DE, Clemencon B \& Hediger MA (2013) Proton-coupled oligopeptide transporter family SLC15: physiological, pharmacological and pathological implications. Mol Aspects Med 34, 323-336.
27. Brandsch M \& Brandsch C (2003) Intestinal transport of amino acids, peptides and proteins. In Progress in Research on Energy and Protein Metabolism, pp. 667-680 [WB Souffrant and CC Metges, editors]. Wageningen: Wageningen Academy Press.

28. Menard S, Cerf-Bensussan N \& Heyman M (2010) Multiple facets of intestinal permeability and epithelial handling of dietary antigens. Mucosal Immunol 3, 247-259.

29. Chabance B, Marteau P, Rambaud JC, et al. (1998) Casein peptide release and passage to the blood in humans during digestion of milk or yogurt. Biochimie 80, 155-165.

30. Chabance B, Jolles P, Izquierdo C, et al. (1995) Characterization of an antithrombotic peptide from $\kappa$-casein in newborn plasma after milk ingestion. Br J Nutr 73, 583-590.

31. Meisel H \& FitzGerald RJ (2000) Opioid peptides encrypted in intact milk protein sequences. Br J Nutr 84, S27-S31.

32. Miner-Williams WM, Stevens BR \& Moughan PJ (2014) Are intact peptides absorbed from the healthy gut in the adult human? Nutr Res Rev 27, 308-329.

33. Izcue A, Coombes JL \& Powrie F (2006) Regulatory T cells suppress systemic and mucosal immune activation to control intestinal inflammation. Immunol Rev 212, 256-271.

34. Strobel S \& Mowat AM (1998) Immune responses to dietary antigens: oral tolerance. Immunol Today 19, 173-181.

35. Goll R \& Granlund AV (2015) Intestinal barrier homeostasis in inflammatory bowel disease. Scand J Gastroenterol 50, 3-12.

36. Cani PD, Bibiloni R, Knauf C, et al. (2008) Changes in gut microbiota control metabolic endotoxemia-induced inflammation in high-fat diet-induced obesity and diabetes in mice. Diabetes 57, 1470-1481.

37. Furuse M, Fujita K, Hiiragi T, et al. (1998) Claudin-1 and -2: novel integral membrane proteins localizing at tight junctions with no sequence similarity to occludin. J Cell Biol 141, 1539-1550.

38. Furuse M, Hirase T, Itoh M, et al. (1993) Occludin: a novel integral membrane-protein localizing at tight junctions. J Cell Biol 123, 1777-1788.

39. Mandell KJ, McCall IC \& Parkos CA (2004) Involvement of the junctional adhesion molecule-1 (JAM1) homodimer interface in regulation of epithelial barrier function. $J$ Biol Chem 279, 16254-16262.

40. Ikenouchi J, Furuse M, Furuse K, et al. (2005) Tricellulin constitutes a novel barrier at tricellular contacts of epithelial cells. J Cell Biol 171, 939-945.

41. Vermeirssen V, Van Camp J \& Verstraete W (2004) Bioavailability of angiotensin I converting enzyme inhibitory peptides. BrJ Nutr $\mathbf{9 2}, 357-366$.

42. Arrieta MC, Bistritz L \& Meddings JB (2006) Alterations in intestinal permeability. Gut 55, 1512-1520.

43. Madsen KL, Malfair D, Gray D, et al. (1999) Interleukin-10 gene-deficient mice develop a primary intestinal permeability defect in response to enteric microflora. Inflamm Bowel Dis 5, 262-270.

44. Raddatz D, Bockemuhl M \& Ramadori G (2005) Quantitative measurement of cytokine mRNA in inflammatory bowel disease: relation to clinical and endoscopic activity and outcome. Eur J Gastroenterol Hepatol 17, 547-557.

45. Stallmach A, Giese T, Schmidt C, et al. (2004) Cytokine/ chemokine transcript profiles reflect mucosal inflammation in Crohn's disease. Int J Colorectal Dis 19, 308-315.

46. Gassler N, Rohr C, Schneider A, et al. (2001) Inflammatory bowel disease is associated with changes of enterocytic junctions. Am J Physiol Gastrointest Liver Physiol 281, G216-G228. 
47. Kucharzik T, Walsh SV, Chen J, et al. (2001) Neutrophil transmigration in inflammatory bowel disease is associated with differential expression of epithelial intercellular junction proteins. Am J Pathol 159, 2001-2009.

48. Bruewer M, Luegering A, Kucharzik T, et al. (2003) Proinflammatory cytokines disrupt epithelial barrier function by apoptosis-independent mechanisms. J Immunol 171, 6164-6172.

49. Utech M, Ivanov AI, Samarin SN, et al. (2005) Mechanism of IFN- $\gamma$-induced endocytosis of tight junction proteins: myosin II-dependent vacuolarization of the apical plasma membrane. Mol Biol Cell 16, 5040-5052.

50. Matsuda M, Kubo A, Furuse M, et al. (2004) A peculiar internalization of claudins, tight junction-specific adhesion molecules, during the intercellular movement of epithelial cells. J Cell Sci 117, 1247-1257.

51. Bojarski C, Gitter AH, Bendfeldt K, et al. (2001) Permeability of human HT-29/B6 colonic epithelium as a function of apoptosis. J Physiol 535, 541-552.

52. Schulzke JD, Bojarski C, Zeissig S, et al. (2006) Disrupted barrier function through epithelial cell apoptosis. Ann $N Y$ Acad Sci 1072, 288-299.

53. Begue B, Wajant H, Bambou JC, et al. (2006) Implication of TNF-related apoptosis-inducing ligand in inflammatory intestinal epithelial lesions. Gastroenterology 130, 1962-1974.

54. Mankertz J, Tavalali S, Schmitz H, et al. (2000) Expression from the human occludin promoter is affected by tumor necrosis factor $\alpha$ and interferon $\gamma$.J Cell Sci 113, 2085-2090.

55. Zolotarevsky Y, Hecht G, Koutsouris A, et al. (2002) A membrane-permeant peptide that inhibits MLC kinase restores barrier function in in vitro models of intestinal disease. Gastroenterology 123, 163-172.

56. Turner JR (2009) Intestinal mucosal barrier function in health and disease. Nat Rev Immunol 9, 799-809.

57. Mennigen R, Nolte K, Rijcken E, et al. (2009) Probiotic mixture VSL\#3 protects the epithelial barrier by maintaining tight junction protein expression and preventing apoptosis in a murine model of colitis. Am J Physiol Gastrointest Liver Physiol 296, G1140-G1149.

58. Gionchetti P, Rizzello F, Morselli C, et al. (2007) High-dose probiotics for the treatment of active pouchitis. Dis Colon Rectum 50, 2075-2082.

59. Bai YH, Pak SC, Lee SH, et al. (2005) Assessment of a bioactive compound for its potential antiinflammatory property by tight junction permeability. Phytother Res 19, 1009-1012.

60. Parassol N, Freitas M, Thoreux K, et al. (2005) Lactobacillus casei DN-114 001 inhibits the increase in paracellular permeability of enteropathogenic Escherichia coli-infected T84 cells. Res Microbiol 156, 256-262.

61. Resta-Lenert S \& Barrett KE (2006) Probiotics and commensals reverse TNF- $\alpha$ - and IFN- $\gamma$-induced dysfunction in human intestinal epithelial cells. Gastroenterology 130, 731-746.

62. Zyrek AA, Cichon C, Helms S, et al. (2007) Molecular mechanisms underlying the probiotic effects of Escherichia coli Nissle 1917 involve ZO-2 and PKC zeta redistribution resulting in tight junction and epithelial barrier repair. Cell Microbiol 9, 804-816.

63. Ukena SN, Singh A, Dringenberg U, et al. (2007) Probiotic Escherichia coli Nissle 1917 Inhibits leaky gut by enhancing mucosal integrity. PLOS ONE 2, e1308.

64. Miyauchi E, Morita H \& Tanabe S (2009) Lactobacillus rhamnosus alleviates intestinal barrier dysfunction in part by increasing expression of zonula occludens- 1 and myosin light-chain kinase in vivo. J Dairy Sci 92, 2400-2408.
65. Chen HQ, Yang J, Zhang M, et al. (2010) Lactobacillus plantarum ameliorates colonic epithelial barrier dysfunction by modulating the apical junctional complex and PepT1 in IL-10 knockout mice. Am J Physiol Gastrointest Liver Physiol 299, G1287-G1297.

66. Ewaschuk JB, Diaz H, Meddings L, et al. (2008) Secreted bioactive factors from Bifidobacterium infantis enhance epithelial cell barrier function. Am J Physiol Gastrointest Liver Physiol 295, G1025-G1034.

67. Keita AV, Gullberg E, Ericson AC, et al. (2006) Characterization of antigen and bacterial transport in the follicle-associated epithelium of human ileum. Lab Invest 86, 504-516.

68. Keita AC, Salim S, Jiang T, et al. (2008) Increased uptake of non-pathogenic E. coli via the follicle-associated epithelium in longstanding ileal Crohn's disease. J Pathol 215, 135-144.

69. Rescigno M, Rotta G, Valzasina B, et al. (2001) Dendritic cells shuttle microbes across gut epithelial monolayers. Immunobiology 204, 572-581.

70. Shimizu M, Tsunogai M \& Arai S (1997) Transepithelial transport of oligopeptides in the human intestinal cell, Caco-2. Peptides 18, 681-687.

71. Shen WC, Wan JS \& Ekrami H (1992) Enhancement of polypeptide and protein-absorption by macromolecular carriers via endocytosis and transcytosis 3. Adv Drug Deliver $\operatorname{Rev} \mathbf{8}, 93-113$.

72. Van Niel G, Mallegol J, Bevilacqua C, et al. (2003) Intestinal epithelial exosomes carry MHC class II/peptides able to inform the immune system in mice. Gut 52, 1690-1697.

73. Mallegol J, Van Niel G, Lebreton C, et al. (2007) T84-intestinal epithelial exosomes bear MHC class II/peptide complexes potentiating antigen presentation by dendritic cells. Gastroenterology 132, 1866-1876.

74. Fernandez MI, Pedron T, Tournebize R, et al. (2003) Anti-inflammatory role for intracellular dimeric immunoglobulin a by neutralization of lipopolysaccharide in epithelial cells. Immunity 18, 739-749.

75. Matysiak-Budnik T, Moura IC, Arcos-Fajardo M, et al. (2008) Secretory IgA mediates retrotranscytosis of intact gliadin peptides via the transferrin receptor in celiac disease. J Exp Med 205, 143-154.

76. Brambell FW (1966) Transmission of immunity from mother to young and catabolism of immunoglobulins. Lancet iii, 1087-1093

77. Jones EA \& Waldmann TA (1971) Mechanism of intestinal uptake and transcellular transport of IgG in neonatal rat. Gut 12, 855-856.

78. Yoshida M, Kobayashi K, Kuo TT, et al. (2006) Neonatal Fc receptor for $\operatorname{IgG}$ regulates mucosal immune responses to luminal bacteria. J Clin Invest 116, 2142-2151.

79. Kobayashi K, Qiao SW, Yoshida M, et al. (2009) An FcRn-dependent role for anti-flagellin immunoglobulin $\mathrm{G}$ in pathogenesis of colitis in mice. Gastroenterology 137, $1746-1756$

80. Kaiserlian D, Lachaux A, Grosjean I, et al. (1993) Intestinal epithelial cells express the CD23/Fc epsilon RII molecule: enhanced expression in enteropathies. Immunology 80, 90-95.

81. Soderholm JD, Olaison G, Hedman L, et al. (1996) Crohn's disease: a hyperreactivity of the tight junctions? Gut 39, A167.

82. Soderholm JD, Streutker C, Yang PC, et al. (2004) Increased epithelial uptake of protein antigens in the ileum of Crohn's disease mediated by tumour necrosis factor $\alpha$. Gut 53, 1817-1824.

83. D'Haens G (2009) Anti-TNF- $\alpha$ treatment strategies: results and clinical perspectives. Gastroenterol Clin Biol 33, S209-S216. 
84. Terpend K, Boisgerault F, Blaton MA, et al. (1998) Protein transport and processing by human HT29-19A intestinal cells: effect of interferon $\gamma$. Gut $\mathbf{4 2}, 538-545$.

85. Goodacre R (2007) Metabolomics of a superorganism. J Nutr 137, 259S-266S.

86. Wilson A, Teft WA, Morse BL, et al. (2015) TrimethylamineN-oxide: a novel biomarker for the identification of inflammatory bowel disease. Dig Dis Sci 60, 3620-3630.

87. Gill SR, Pop M, DeBoy RT, et al. (2006) Metagenomic analysis of the human distal gut microbiome. Science 312, 1355-1359.

88. Wu GD, Chen J, Hoffmann C, et al. (2011) Linking long-term dietary patterns with gut microbial enterotypes. Science 334, 105-108.

89. Sartor RB (2008) Microbial influences in inflammatory bowel diseases. Gastroenterology 134, 577-594.

90. Matsuoka K \& Kanai T (2015) The gut microbiota and inflammatory bowel disease. Semin Immunopatbol 37, $47-55$.

91. Jia WJ, Whitehead RN, Griffiths L, et al. (2012) Diversity and distribution of sulphate-reducing bacteria in human faeces from healthy subjects and patients with inflammatory bowel disease. FEMS Immunol Med Microbiol 65, 55-68.

92. Bibiloni R, Mangold M, Madsen KL, et al. (2006) The bacteriology of biopsies differs between newly diagnosed, untreated, Crohn's disease and ulcerative colitis patients. J Med Microbiol 55, 1141-1149.

93. Chassaing B \& Darfeuille-Michaud A (2011) The commensal microbiota and enteropathogens in the pathogenesis of inflammatory bowel diseases. Gastroenterology 140, $1720-1728$.

94. Frank DN, Amand ALS, Feldman RA, et al. (2007) Molecularphylogenetic characterization of microbial community imbalances in human inflammatory bowel diseases. Proc Natl Acad Sci U S A 104, 13780-13785.

95. van der Waaij LA, Kroese FGM, Visser A, et al. (2004) Immunoglobulin coating of faecal bacteria in inflammatory bowel disease. Eur J Gastroenterol Hepatol 16, 669-674.

96. Pitcher MCL, Beatty ER \& Cummings JH (2000) The contribution of sulphate reducing bacteria and 5-aminosalicylic acid to faecal sulphide in patients with ulcerative colitis. Gut 46, 64-72.

97. Zinkevich V \& Beech IB (2000) Screening of sulfate-reducing bacteria in colonoscopy samples from healthy and colitic human gut mucosa. FEMS Microbiol Ecol 34, 147-155.

98. Duffy M, O'Mahony L, Coffey JC, et al. (2002) Sulfatereducing bacteria colonize pouches formed for ulcerative colitis but not for familial adenomatous polyposis. Dis Colon Rectum 45, 384-388.

99. Ohge H, Furne JK, Springfield J, et al. (2005) Association between fecal hydrogen sulfide production and pouchitis. Dis Colon Rectum 48, 469-475.

100. Manichanh C, Rigottier-Gois L, Bonnaud E, et al. (2006) Reduced diversity of faecal microbiota in Crohn's disease revealed by a metagenomic approach. Gut 55, 205-211.

101. Carmen Collado M \& Sanz Y (2007) Quantification of mucosa-adhered microbiota of lambs and calves by the use of culture methods and fluorescent in situ hybridization coupled with flow cytometry techniques. Vet Microbiol 121, 299-306.

102. Shatalin K, Shatalina A, Mironov A, et al. (2011) H2S: a universal defense against antibiotics in bacteria. Science 335, 986-990

103. Marquet P, Duncan SH, Chassard C, et al. (2009) Lactate has the potential to promote hydrogen sulphide formation in the human colon. FEMS Microbiol Lett 299, 128-134.
104. Giaffer MH, Clark A \& Holdsworth CD (1992) Antibodies to Saccharomyces cerevisiae in patients with Crohn's disease and their possible pathogenic importance. Gut 33, 1071-1075.

105. Rescigno M (2011) The intestinal epithelial barrier in the control of homeostasis and immunity. Trends Immunol 32, 256-264.

106. Qin JJ, Li RQ, Raes J, et al. (2010) A human gut microbial gene catalogue established by metagenomic sequencing. Nature 464, 59-65.

107. Willing BP, Dicksved J, Halfvarson J, et al. (2010) A pyrosequencing study in twins shows that gastrointestinal microbial profiles vary with inflammatory bowel disease phenotypes. Gastroenterology 139, 1844-1854.e1.

108. Willing B, Halfvarson J, Dicksved J, et al. (2009) Twin studies reveal specific imbalances in the mucosa-associated microbiota of patients with ileal Crohn's disease. Inflamm Bowel Dis 15, 653-660.

109. Frank DN, Robertson CE, Hamm CM, et al. (2011) Disease phenotype and genotype are associated with shifts in intestinal-associated microbiota in inflammatory bowel diseases. Inflamm Bowel Dis 17, 179-184.

110. Packey CD \& Sartor RB (2009) Commensal bacteria, traditional and opportunistic pathogens, dysbiosis and bacterial killing in inflammatory bowel diseases. Curr Opin Infect Dis 22, 292-301.

111. Sokol H, Lay C, Seksik P, et al. (2008) Analysis of bacterial bowel communities of IBD patients: what has it revealed? Inflamm Bowel Dis 14, 858-867.

112. Feng T \& Elson CO (2011) Adaptive immunity in the hostmicrobiota dialog. Mucosal Immunol 4, 15-21.

113. Konrad A, Cong YZ, Duck W, et al. (2006) Tight mucosal compartmentation of the murine immune response to antigens of the enteric microbiota. Gastroenterology 130, 2050-2059.

114. Slack E, Hapfelmeier S, Stecher B, et al. (2009) Innate and adaptive immunity cooperate flexibly to maintain host-microbiota mutualism. Science 325, 617-620.

115. Sartor RB (2010) Genetics and environmental interactions shape the intestinal microbiome to promote inflammatory bowel disease versus mucosal homeostasis. Gastroenterology 139, 1816-1819.

116. Abraham C \& Cho JH (2009) Inflammatory bowel disease. New Engl J Med 361, 2066-2078.

117. Cadwell K, Liu JY, Brown SL, et al. (2008) A key role for autophagy and the autophagy gene Atg16l1 in mouse and human intestinal Paneth cells. Nature 456, 259-263.

118. Wehkamp J, Salzman NH, Porter E, et al. (2005) Reduced Paneth cell $\alpha$-defensins in ileal Crohn's disease. Proc Natl Acad Sci U S A 102, 18129-18134.

119. Hill AB (1965) Environment and disease: association or causation? Proc R SOC Med 58, 295-300.

120. Evans AS (1976) Causation and disease: Henle-Koch postulates revisited. Yale J Biol Med 49, 175-195.

121. Fredricks DN \& Relman DA (1996) Sequence-based identification of microbial pathogens: a reconsideration of Koch's postulates. Clin Microbiol Rev 9, 18-33.

122. Sepehri S, Kotlowski R, Bernstein CN, et al. (2007) Microbial diversity of inflamed and noninflamed gut biopsy tissues in inflammatory bowel disease. Inflamm Bowel Dis 13, 675-683.

123. Seksik P, Lepage P, de la Cochetiere MF, et al. (2005) Search for localized dysbiosis in Crohn's disease ulcerations by temporal temperature gradient gel electrophoresis of 16S rRNA. J Clin Microbiol 43, 4654-4658.

124. Walker AW, Sanderson JD, Churcher C, et al. (2011) High-throughput clone library analysis of the mucosaassociated microbiota reveals dysbiosis and differences 
between inflamed and non-inflamed regions of the intestine in inflammatory bowel disease. BMC Microbiol 11, 7 .

125. Quigley EMM (2011) Commensal bacteria: the link between IBS and IBD? Curr Opin Clin Nutr Metab Care 14, 497-503.

126. Sartor RB (2011) Key questions to guide a better understanding of host-commensal microbiota interactions in intestinal inflammation. Mucosal Immunol 4, 127-132.

127. Sokol H, Pigneur B, Watterlot L, et al. (2008) Faecalibacterium prausnitzii is an anti-inflammatory commensal bacterium identified by gut microbiota analysis of Crohn disease patients. Proc Natl Acad Sci U S A 105, 16731-16736.

128. Swidsinski A, Loening-Baucke $\mathrm{V}$, Vaneechoutte $\mathrm{M}$, et al. (2008) Active Crohn's disease and ulcerative colitis can be specifically diagnosed and monitored based on the biostructure of the fecal flora. Inflamm Bowel Dis 14, 147-161.

129. Maldonado-Contreras AL \& McCormick BA (2011) Intestinal epithelial cells and their role in innate mucosal immunity. Cell Tissue Res 343, 5-12.

130. Fyderek K, Strus M, Kowalska-Duplaga K, et al. (2009) Mucosal bacterial microflora and mucus layer thickness in adolescents with inflammatory bowel disease. World $J$ Gastroenterol 15, 5287-5294.

131. Corfield AP (2015) Mucins: a biologically relevant glycan barrier in mucosal protection. Biochim Biophys Acta 1850, 236-252.

132. Joossens M, Huys G, Cnockaert M, et al. (2011) Dysbiosis of the faecal microbiota in patients with Crohn's disease and their unaffected relatives. Gut 60, 631-637.

133. Kufer TA \& Sansonetti PJ (2007) Sensing of bacteria: NOD a lonely job. Curr Opin Microbiol 10, 62-69.

134. Wilmanski JM, Petnicki-Ocwieja T \& Kobayashi KS (2008) NLR proteins: integral members of innate immunity and mediators of inflammatory diseases. J Leukoc Biol 83, 13-30.

135. Girardin SE, Travassos LH, Herve M, et al. (2003) Peptidoglycan molecular requirements allowing detection by Nod1 and Nod2. J Biol Chem 278, 41702-41708.

136. Girardin SE, Boneca IG, Carneiro LAM, et al. (2003) Nod1 detects a unique muropeptide from Gram-negative bacterial peptidoglycan. Science 300, 1584-1587.

137. Chamaillard M, Hashimoto M, Horie Y, et al. (2003) An essential role for NOD1 in host recognition of bacterial peptidoglycan containing diaminopimelic acid. Nat Immunol 4, 702-707.

138. Girardin SE, Boneca IG, Viala J, et al. (2003) Nod2 is a general sensor of peptidoglycan through muramyl dipeptide (MDP) detection. J Biol Chem 278, 8869-8872.

139. Inohara N, Ogura Y, Fontalba A, et al. (2003) Host recognition of bacterial muramyl dipeptide mediated through NOD2. J Biol Chem 278, 5509-5512.

140. Le Bourhis L, Benko S \& Girardin SE (2007) Nod1 and Nod2 in innate immunity and human inflammatory disorders. Biochem Soc Trans 35, 1479-1484.

141. Hugot JP, Chamaillard M, Zouali H, et al. (2001) Association of NOD2 leucine-rich repeat variants with susceptibility to Crohn's disease. Nature 411, 599-603.

142. Ogura Y, Bonen DK, Inohara N, et al. (2001) A frameshift mutation in NOD2 associated with susceptibility to Crohn's disease. Nature 411, 603-606.

143. Wehkamp J, Schmid M \& Stange EF (2007) Defensins and other antimicrobial peptides in inflammatory bowel disease. Curr Opin Gastroenterol 23, 370-378.

144. Bevins CL, Martin-Porter E \& Ganz T (1999) Defensins and innate host defence of the gastrointestinal tract. Gut 271, 14038-14045.

145. Ayabe T, Satchell DP, Wilson CL, et al. (2000) Secretion of microbicidal $\alpha$-defensins by intestinal Paneth cells in response to bacteria. Nat Immunol 1, 113-118.
146. Khan J \& Islam MN (2011) Intestinal barrier function: impairment and possible modulation. Int Med J 18, 212-216.

147. Astwood JD, Leach JN \& Fuchs RL (1996) Stability of food allergens to digestion in vitro. Nat Biotechnol 14, 1269-1273.

148. Mahé S, Messing B, Thuillier F, et al. (1991) Digestion of bovine milk proteins in patients with a high jejunostomy. Am J Clin Nutr 54, 534-538.

149. Shan L, Molberg O, Parrot I, et al. (2002) Structural basis for gluten intolerance in celiac sprue. Science 297, 2275-2279.

150. Shan L, Qiao SW, Arentz-Hansen H, et al. (2005) Identification and analysis of multivalent proteolytically resistant peptides from gluten: implications for celiac sprue. J Proteome Res 4, 1732-1741.

151. Diesner SC, Knittelfelder R, Krishnamurthy D, et al. (2008) Dose-dependent food allergy induction against ovalbumin under acid-suppression: a murine food allergy model. Immunol Lett 121, 45-51.

152. Estaki M, DeCoffe D \& Gibson DL (2014) Interplay between intestinal alkaline phosphatase, diet, gut microbes and immunity. World J Gastroenterol 20, 15650-15656.

153. Lalles JP (2014) Intestinal alkaline phosphatase: novel functions and protective effects. Nutr Rev 72, 82-94

154. Wang W, Chen SW, Zhu J, et al. (2015) Intestinal alkaline phosphatase inhibits the translocation of bacteria of gut-origin in mice with peritonitis: mechanism of action. PLOS ONE 10, e0124835.

155. Martínez-Augustin O, López-Posadas R, González R, et al. (2010) It may not be intestinal, but tissue non-specific alkaline phosphatase. Gut 59, 560.

156. Molnar K, Vannay A, Sziksz E, et al. (2012) Decreased mucosal expression of intestinal alkaline phosphatase in children with coeliac disease. Virchows Archiv 460, 157-161.

157. Tuin A, Poelstra K, de Jager-Krikken A, et al. (2009) Role of alkaline phosphatase in colitis in man and rats. Gut $\mathbf{5 8}$, 379-387.

158. Lukas M, Drastich P, Konecny M, et al. (2010) Exogenous alkaline phosphatase for the treatment of patients with moderate to severe ulcerative colitis. Inflamm Bowel Dis $\mathbf{1 6}$, 1180-1186.

159. Weersma RK, Stokkers PCF, van Bodegraven AA, et al. (2009) Molecular prediction of disease risk and severity in a large Dutch Crohn's disease cohort. Gut 58, 388-395.

160. Ellinghaus D, Bethune J, Petersen BS, et al. (2015) The genetics of Crohn's disease and ulcerative colitis - status quo and beyond. Scand J Gastroenterol 50, 13-23.

161. Qin XF (2012) Etiology of inflammatory bowel disease: a unified hypothesis. World J Gastroenterol 18, 1708-1722.

162. Ferguson LR (2013) Nutrigenetics, nutrigenomics and inflammatory bowel diseases. Expert Rev Clin Immunol 9 , 717-726.

163. Ferguson LR (2010) Nutrigenomics and inflammatory bowel diseases. Expert Rev Clin Immunol 6, 573-583.

164. Graham DB \& Xavier RJ (2013) From genetics of inflammatory bowel disease towards mechanistic insights. Trends Immunol 34, 371-378.

165. Neuman MG \& Nanau RM (2012) Single-nucleotide polymorphisms in inflammatory bowel disease. Transl Res $\mathbf{1 6 0}$, 45-64.

166. Gardet A \& Xavier RJ (2012) Common alleles that influence autophagy and the risk for inflammatory bowel disease. Curr Opin Immunol 24, 522-529.

167. Cheon JH (2013) Genetics of inflammatory bowel diseases: a comparison between Western and Eastern perspectives. J Gastroenterol Hepatol 28, 220-226.

168. Stange EF (2013) Inflammatory bowel disease: the past 50 years [article in German]. Z Gastroenterol 51, 371-377. 
169. Boirivant M \& Cossu A (2012) Inflammatory bowel disease. Oral Dis 18, 1-15.

170. Satokari R (2015) Contentious host-microbiota relationship in inflammatory bowel disease - can foes become friends again? Scand J Gastroenterol 50, 34-42.

171. Jostins L, Ripke S, Weersma RK, et al. (2012) Host-microbe interactions have shaped the genetic architecture of inflammatory bowel disease. Nature 491, 119-124.

172. Thompson AI \& Lees CW (2011) Genetics of ulcerative colitis. Inflamm Bowel Dis 17, 831-848.

173. Rivas MA, Beaudoin M, Gardet A, et al. (2011) Deep resequencing of GWAS loci identifies independent rare variants associated with inflammatory bowel disease. Nat Genet $\mathbf{4 3}$, 1066-1073.

174. Khor B, Gardet A \& Xavier RJ (2011) Genetics and pathogenesis of inflammatory bowel disease. Nature $\mathbf{4 7 4}$, 307-317.

175. Viennois E, Baker MT, Xiao B, et al. (2015) Longitudinal study of circulating protein biomarkers in inflammatory bowel disease. J Proteomics 112, 166-179.

176. Hu YG, Smith DE, Ma K, et al. (2008) Targeted disruption of peptide transporter pept 1 gene in mice significantly reduces dipeptide absorption in intestine. Mol Pharm 5, 1122-1130.

177. Russel MG (2000) Changes in the incidence of inflammatory bowel disease: what does it mean? Eur J Intern Med 11, 191-196.

178. Steel A, Nussberger S, Romero MF, et al. (1997) Stoichiometry and $\mathrm{pH}$ dependence of the rabbit proton-dependent oligopeptide transporter PepT1. J Physiol 498, 563-569.

179. Boll M, Markovich D, Weber WM, et al. (1994) Expression cloning of a cDNA from rabbit small intestine related to proton-coupled transport of peptides, $\beta$-lactam antibiotics and ACE-inhibitors. Pflugers Arch 429, 146-149.

180. Qin X (2007) Inactivation of digestive proteases by deconjugated bilirubin: the possible evolutionary driving force for bilirubin or biliverdin predominance in animals. Gut $\mathbf{5 6}$, 1641-1642.

181. Qin XF (2002) Impaired inactivation of digestive proteases by deconjugated bilirubin: the possible mechanism for inflammatory bowel disease. Med Hypotheses 59, 159-163.

182. Ogihara H, Saito H, Shin BC, et al. (1996) Immunolocalization of $\mathrm{H}^{+}$/peptide cotransporter in rat digestive tract. Biochem Biophys Res Commun 220, 848-852.

183. Ismair MG, Vavricka SR, Kullak-Ublick GA, et al. (2006) hPepT1 selectively transports muramyl dipeptide but not Nod1-activating muramyl peptides. Can J Physiol Pharmacol 84, 1313-1319.

184. Weitz D, Harder D, Casagrande F, et al. (2007) Functional and structural characterization of a prokaryotic peptide transporter with features similar to mammalian PEPT1. J Biol Chem 282, 2832-2839.

185. Daniel H (2004) Molecular and integrative physiology of intestinal peptide transport. Annu Rev Physiol 66, 361-384.

186. Bailey PD, Boyd CAR, Collier ID, et al. (2006) Affinity prediction for substrates of the peptide transporter PepT1. Chem Commun 21, 323-325.

187. Spanier B (2014) Transcriptional and functional regulation of the intestinal peptide transporter PEPT1. J Physiol 592, 871-879.

188. Watanabe C, Kato $\mathrm{Y}$, Ito S, et al. (2005) $\mathrm{Na}^{+} / \mathrm{H}^{+}$exchanger 3 affects transport property of $\mathrm{H}^{+}$/oligopeptide transporter 1 . Drug Metab Pharmacokinet 20, 443-451.

189. Vavricka SR, Musch MW, Fujiya M, et al. (2006) Tumor necrosis factor- $\alpha$ and interferon- $\gamma$ increase PepT1 expression and activity in the human colon carcinoma cell line Caco-2/ bbe and in mouse intestine. Pflugers Arch 452, 71-80.
190. Zucchelli M, Torkvist L, Bresso F, et al. (2009) PepT1 oligopeptide transporter (SLC15A1) gene polymorphism in inflammatory bowel disease. Inflamm Bowel Dis 15, 1562-1569.

191. Strober W, Asano N, Fuss I, et al. (2014) Cellular and molecular mechanisms underlying NOD2 risk-associated polymorphisms in Crohn's disease. Immunol Rev 260, 249-260.

192. Freeman HJ (2015) Clinical relevance of intestinal peptide uptake. World J Gastrointest Pharm Ther 6, 22-27.

193. Nassl A-M, Rubio-Aliaga I, Fenselau H, et al. (2011) Amino acid absorption and homeostasis in mice lacking the intestinal peptide transporter PEPT1. Am J Physiol Gastrointest Liver Physiol 301, G128-G137.

194. Nataro JP \& Kaper JB (1998) Diarrheagenic Escherichia coli. Clin Microbiol Rev 11, 142-201.

195. Nguyen HTT, Dalmasso G, Powell KR, et al. (2009) Pathogenic bacteria induce colonic PepT1 expression: an implication in host defense response. Gastroenterology $\mathbf{1 3 7}$, $1435-1447$.

196. Merlin D, Steel A, Gewirtz AT, et al. (1998) hPepT1-mediated epithelial transport of bacteria-derived chemotactic peptides enhances neutrophil-epithelial interactions. J Clin Invest 102, 2011-2018.

197. Vavricka SR, Musch MW, Chang JE, et al. (2004) hPepT1 transports muramyl dipeptide, activating NF- $\mathrm{KB}$ and stimulating IL-8 secretion in human colonic $\mathrm{Caco} 2 / \mathrm{bbe}$ cells. Gastroenterology 127, 1401-1409.

198. Dalmasso G, Hang TTN, Ingersoll SA, et al. (2011) The PepT1-NOD2 signaling pathway aggravates induced colitis in mice. Gastroenterology 141, 1334-1345.

199. Foster DR \& Zheng X (2007) Cephalexin inhibits $\mathrm{N}$-formylated peptide transport and intestinal hyperpermeability in Caco2 cells. J Pharm Pharm Sci 10, 299-310.

200. Dalmasso G, Yan Y, Charrier L, et al. (2007) Butyrate transcriptionally enhances peptide transporter (hPepT1) expression and activity. FASEB J 21, A586-A586.

201. Bhardwaj RK, Herrera-Ruiz D, Eltoukhy N, et al. (2006) The functional evaluation of human peptide/histidine transporter 1 (hPHT1) in transiently transfected COS-7 cells. Eur J Pharm Sci 27, 533-542.

202. Wu SP \& Smith DE (2013) Impact of intestinal PepT1 on the kinetics and dynamics of $\mathrm{N}$-formyl-methionyl-leucyl-phenylalanine, a bacterially-produced chemotactic peptide. Mol Pharm 10, 677-684.

203. Tsuji A, Nakashima E, Deguchi Y, et al. (1981) Degradation kinetics and mechanism of aminocephalosporins in aqueous solution: cefadroxil. J Pharm Sci 70, 1120-1128.

204. Walker D, Thwaites DT, Simmons NL, et al. (1998) Substrate upregulation of the human small intestinal peptide transporter, hPepT1. J Physiol 507, 697-706.

205. Huebner C, Browning BL, Petermann I, et al. (2009) Genetic analysis of MDR1 and inflammatory bowel disease reveals protective effect of heterozygous variants for ulcerative colitis. Inflamm Bowel Dis 15, 1784-1793.

206. Sakata K, Yamashita T, Maeda M, et al. (2001) Cloning of a lymphatic peptide/histidine transporter. Biochem J 356, 53-60.

207. Potocnik U, Ferkolj I, Glavac D, et al. (2004) Polymorphisms in multidrug resistance 1 (MDR1) gene are associated with refractory Crohn disease and ulcerative colitis. Genes Immun 5, 530-539.

208. Sabbah A, Chang TH, Harnack R, et al. (2009) Activation of innate immune antiviral responses by Nod2. Nat Immunol 10, 1073-1080.

209. Garrett WS, Gallini CA, Yatsunenko T, et al. (2010) Enterobacteriaceae act in concert with the gut microbiota to induce spontaneous and maternally transmitted colitis. Cell Host Microbe 8, 292-300. 
210. Molodecky NA, Soon IS, Rabi DM, et al. (2012) Increasing incidence and prevalence of the inflammatory bowel diseases with time, based on systematic review. Gastroenterology 142, 46-54.

211. Merlin D, Si-Tahar M, Sitaraman SV, et al. (2001) Colonic epithelial hPepT1 expression occurs in inflammatory bowel disease: transport of bacterial peptides influences expression of MHC class 1 molecules. Gastroenterology 120, 1666-1679.

212. Nduati V, Yan YT, Dalmasso G, et al. (2007) Leptin transcriptionally enhances peptide transporter (hPepT1) expression and activity via the cAMP-response elementbinding protein and $\mathrm{Cdx} 2$ transcription factors. $J$ Biol Chem 282, 1359-1373.

213. Ziegler TR, Fernández-Estívariz C, Gu LH, et al. (2002) Distribution of the $\mathrm{H}^{+}$/peptide transporter PepT1 in human intestine: up-regulated expression in the colonic mucosa of patients with short-bowel syndrome. Am J Clin Nutr $\mathbf{7 5}$, 922-930.

214. Shimakura J, Terada T, Shimada Y, et al. (2006) The transcription factor Cdx2 regulates the intestine-specific expression of human peptide transporter 1 through functional interaction with Sp1. Biochem Pharmacol 71, 1581-1588.

215. Metges CC (2000) Contribution of microbial amino acids to amino acid homeostasis of the host. J Nutr 130, 1857S-1864S.

216. Whitman WB, Coleman DC \& Wiebe WJ (1998) Prokaryotes: the unseen majority. Proc Natl Acad Sci U S A 95, 6578-6583.

217. Garrett WS, Lord GM, Punit S, et al. (2007) Communicable ulcerative colitis induced by T-bet deficiency in the innate immune system. Cell 131, 33-45.

218. Davies PS \& Rhodes J (1978) Maintenance of remission in ulcerative colitis with sulphasalazine or a high-fibre diet: a clinical trial. Br Med Ji i, 1524-1525.

219. Fernandez-Banares F, Hinojosa J, Sanchez-Lombrana JL, et al. (1999) Randomized clinical trial of Plantago ovata seeds (dietary fiber) as compared with mesalamine in maintaining remission in ulcerative colitis. Am J Gastroenterol 94, 427-433.

220. Wright R \& Truelove SC (1965) A controlled therapeutic trial of various diets in ulcerative colitis. Br Med J ii, 138-141.

221. Samuelsson SM, Ekbom A, Zack M, et al. (1991) Risk factors for extensive ulcerative colitis and ulcerative proctitis: a population based case-control study. Gut 32, 1526-1530.

222. Pithadia AB \& Jain S (2011) Treatment of inflammatory bowel disease (IBD). Pharmacol Rep 63, 629-642.

223. Roediger WEW, Duncan A, Kapaniris O, et al. (1993) Reducing sulfur compounds of the colon impair colonocyte nutrition: implications for ulcerative colitis. Gastroenterology 104, 802-809.

224. Sakamoto N, Kono S, Wakai K, et al. (2005) Dietary risk factors for inflammatory bowel disease: a multicenter casecontrol study in Japan. Inflamm Bowel Dis 11, 154-163.

225. King TS, Woolner JT \& Hunter JO (1997) The dietary management of Crohn's disease. Aliment Pharmacol Ther 11, 17-31.

226. Choi J, Sabikhi L, Hassan A, et al. (2012) Bioactive peptides in dairy products. Int J Dairy Technol 65, 1-12.

227. Meisel H \& FitzGerald RJ (2003) Biofunctional peptides from milk proteins: mineral binding and cytomodulatory effects. Curr Pharm Des 9, 1289-1295.

228. Meisel H (2004) Multifunctional peptides encrypted in milk proteins. Biofactors 21, 55-61.

229. Schmid A (2009) Bioactive substances in meat and meat products. Fleischwirtschaft 89, 83-90.

230. Ryan JT, Ross RP, Bolton D, et al. (2011) Bioactive peptides from muscle sources: meat and fish. Nutrients 3, 765-791.
231. Toldra F \& Reig M (2011) Innovations for healthier processed meats. Trends Food Sci Technol 22, 517-522.

232. Minkiewicz P, Dziuba J \& Michalska J (2011) Bovine meat proteins as potential precursors of biologically active peptides: a computational study based on the BIOPEP Database. Food Sci Technol Int 17, 39-45.

233. Chatterton DEW, Nguyen DN, Bering SB, et al. (2013) Anti-inflammatory mechanisms of bioactive milk proteins in the intestine of newborns. Int J Biochem Cell Biol 45, $1730-1747$.

234. Letterio JJ, Geiser AG, Kulkarni AB, et al. (1994) Maternal rescue of transforming growth factor- $\beta 1$ null mice. Science 264, 1936-1938.

235. Fei YJ, Kanai Y, Nussberger S, et al. (1994) Expression cloning of a mammalian proton-coupled oligopeptide transporter. Nature 368, 563-566.

236. Tanida S, Kataoka H, Mizoshita T, et al. (2010) Intranuclear translocation signaling of HB-EGF carboxy-terminal fragment and mucosal defense through cell proliferation and migration in digestive tracts. Digestion 82, 145-149.

237. Mehta VB \& Besner GE (2005) Heparin-binding epidermal growth factor-like growth factor inhibits cytokine-induced $\mathrm{NF}-\kappa \mathrm{B}$ activation and nitric oxide production via activation of the phosphatidylinositol 3-kinase pathway. J Immunol 175, 1911-1918.

238. Mehta VB \& Besner GE (2003) Inhibition of NF- $\mathrm{B}$ activation and its target genes by heparin-binding epidermal growth factor-like growth factor. I Immunol 171, 6014-6022.

239. Montagne L, Toullec R, Formal M, et al. (2000) Influence of dietary protein level and origin on the flow of mucin along the small intestine of the preruminant calf. J Dairy Sci $\mathbf{8 3}$, 2820-2828.

240. Lien KA, Sauer WC \& He JM (2001) Dietary influences on the secretion into and degradation of mucin in the digestive tract of monogastric animals and humans. J Anim Feed Sci 10, $223-245$.

241. Claustre J, Toumi F, Trompette A, et al. (2002) Effects of peptides derived from dietary proteins on mucus secretion in rat jejunum. Am J Physiol Gastrointest Liver Physiol 283, G521-G528.

242. Han KS, Deglaire A, Sengupta R, et al. (2008) Hydrolyzed casein influences intestinal mucin gene expression in the rat. J Agric Food Chem 56, 5572-5576.

243. Miner-Williams W (2012) The protein composition of endogenous losses in the human gut. http://mro.massey.ac. nz/handle/10179/3401 (accessed April 2016).

244. Trompette A, Claustre J, Caillon F, et al. (2003) Milk bioactive peptides and $\beta$-casomorphins induce mucus release in rat jejunum. J Nutr 133, 3499-3503.

245. Clare DA \& Swaisgood HE (2000) Bioactive milk peptides: a prospectus. J Dairy Sci $\mathbf{8 3}, 1187-1195$.

246. Zoghbi S, Trompette A, Claustre J, et al. (2006) $\beta$-Casomorphin-7 regulates the secretion and expression of gastrointestinal mucins through a mu-opioid pathway. $A m \mathrm{~J}$ Physiol Gastrointest Liver Physiol 290, G1105-G1113.

247. van Klinken BJW, Einerhand AWC, van der Wal JWG, et al. (1998) Quantitative analysis of MUC2 secretion in ulcerative colitis. Gastroenterology 114, A1106-A1106.

248. Van Klinken BJW, Van der Wal JWG, Einerhand AWC, et al. (1999) Sulphation and secretion of the predominant secretory human colonic mucin MUC2 in ulcerative colitis. Gut 44, 387-393.

249. Tytgat KM, Opdam FJM, Einerhand AWC, et al. (1996) MUC2 is the prominent colonic mucin expressed in ulcerative colitis. Gut 38, 554-563. 
250. Tytgat KM, vanderWal JWG, Einerhand AWC, et al. (1996) Quantitative analysis of MUC2 synthesis in ulcerative colitis. Biochem Biophys Res Commun 224, 397-405.

251. Shaoul R, Okada Y, Cutz E, et al. (2004) Colonic expression of MUC2, MUC5AC, and TFF1 in inflammatory bowel disease in children. J Pediatric Gastroenterol Nutr 38, 488-493.

252. Boltin D, Perets TT, Vilkin A, et al. (2013) Mucin function in inflammatory bowel disease: an update. J Clin Gastroenterol 47, 106-111.

253. Xie B \& Costello CE (2008) Carbohydrate structure determination by mass spectrometry. In Carbohydrate Chemistry, Biology and Medical Applications, pp. 29-57 [HG Garg, MK Cowman and CA Hales, editors]. Oxford: Elsevier.

254. Baugh MD, Perry MJ, Hollander AP, et al. (1999) Matrix metalloproteinase levels are elevated in inflammatory bowel disease. Gastroenterology 117, 814-822.

255. Kirkegaard T, Hansen A, Bruun E, et al. (2004) Expression and localisation of matrix metalloproteinases and their natural inhibitors in fistulae of patients with Crohn's disease. Gut 53, 701-709.

256. Castaneda FE, Walia B, Vijay-Kumar M, et al. (2005) Targeted deletion of metalloproteinase 9 attenuates experimental colitis in mice: central role of epithelial-derived MMP. Gastroenterology 129, 1991-2008.

257. Baugh MD, Evans GS, Hollander AP, et al. (1998) Expression of matrix metalloproteases in inflammatory bowel disease. Ann N Y Acad Sci 859, 249-253.

258. Kossakowska AE, Medlicott SAC, Edwards DR, et al. (1999) Elevated plasma gelatinase A (MMP-2) activity is associated with quiescent Crohn's disease. Ann N Y Acad Sci 878, 578-580.

259. Garg P, Ravi A, Patel NR, et al. (2007) Matrix metalloproteinase-9 regulates MUC-2 expression through its effect on goblet cell differentiation. Gastroenterology 132, 1877-1889.

260. Shields JM, Christy RJ \& Yang VW (1996) Identification and characterization of a gene encoding a gut-enriched Kruppellike factor expressed during growth arrest. J Biol Chem 271, 20009-20017.

261. Ng AYN, Waring P, Ristevski S, et al. (2002) Inactivation of the transcript ion factor Elf3 in mice results in dysmorphogenesis and altered differentiation of intestinal epithelium. Gastroenterology 122, 1455-1466.

262. Lammers KM, Lu R, Brownley J, et al. (2008) Gliadin induces an increase in intestinal permeability and zonulin release by binding to the chemokine receptor CXCR3. Gastroenterology 135, 194-204.

263. Fasano A, Not T, Wang W, et al. (2000) Zonulin, a newly discovered modulator of intestinal permeability, and its expression in coeliac disease. Lancet 355, 1518-1519.

264. Green PHR, Lebwohl B \& Greywoode R (2015) Celiac disease. J Allergy Clin Immunol 135, 1099-1106.

265. Heyman M (2005) Gut barrier dysfunction in food allergy. Eur J Gastroenterol Hepatol 17, 1279-1285.

266. Heyman M, Abed J, Lebreton C, et al. (2012) Intestinal permeability in coeliac disease: insight into mechanisms and relevance to pathogenesis. Gut 61, 1355-1364.

267. Perez LC, de Villasante GC, Ruiz AC, et al. (2012) Non-dietary therapeutic clinical trials in coeliac disease. Eur J Intern Med 23, 9-14.

268. Crowe SE (2014) Management of celiac disease: beyond the gluten-free diet. Gastroenterology 146, 1594-1596.

269. Leffler DA, Kelly CP, Abdallah HZ, et al. (2012) A randomized, double-blind study of larazotide acetate to prevent the activation of celiac disease during gluten challenge. Am J Gastroenterol 107, 1554-1562.
270. Kelly CP, Green PHR, Murray JA, et al. (2013) Larazotide acetate in patients with coeliac disease undergoing a gluten challenge: a randomised placebo-controlled study. Aliment Pharmacol Ther 37, 252-262.

271. Spaenij-Dekking L, Kooy-Winkelaar Y, Van Veelen P, et al. (2005) Natural variation in toxicity of wheat: potential for selection of nontoxic varieties for celiac disease patients. Gastroenterology 129, 797-806.

272. Carroccio A, Di Prima L, Noto D, et al. (2011) Searching for wheat plants with low toxicity in celiac disease: between direct toxicity and immunologic activation. Dig Liver Dis $\mathbf{4 3}$, 34-39.

273. Pinier M, Fuhrmann G, Galipeau HJ, et al. (2012) The copolymer P(HEMA-Co-SS) binds gluten and reduces immune response in gluten-sensitized mice and human tissues. Gastroenterology 142, U316-U325.e12.

274. Mitea C, Havenaar R, Drijfhout JW, et al. (2008) Efficient degradation of gluten by a prolyl endoprotease in a gastrointestinal model: implications for coeliac disease. Gut 57, 25-32.

275. Tack GJ, Van de Water JMW, Bruins MJ, et al. (2013) Consumption of gluten with gluten-degrading enzyme by celiac patients: A pilot-study. World J Gastroenterol 19, 5837-5847.

276. Schuppan D, Junker Y \& Barisani D (2009) Celiac disease: from pathogenesis to novel therapies. Gastroenterology 137, 1912-1933.

277. Rauhavirta T, Oittinen M, Kivisto R, et al. (2013) Are transglutaminase 2 inhibitors able to reduce gliadin-induced toxicity related to celiac disease? A proof-of-concept study. J Clin Immunol 33, 134-142.

278. Xia J, Siegel M, Bergseng E, et al. (2006) Inhibition of HLA-DQ2-mediated antigen presentation by analogues of a high affinity 33-residue peptide from $\alpha 2$-gliadin. J Am Chem Soc 128, 1859-1867.

279. Keech CL, Dromey J, Chen ZJ, et al. (2009) Immune tolerance induced by peptide immunotherapy in an HLA Dq2-dependent mouse model of gluten immunity. Gastroenterology 136, A57-A57.

280. Brown GJ, Daveson J, Marjason JK, et al. (2011) A phase 1 study to determine safety, tolerability and bioactivity of Nexvax2® in HLA DQ2 + volunteers with celiac disease following a long-term, strict gluten-free diet. Gastroenterology 140, S437-S438.

281. Heyman M, Grasset E, Ducroc R, et al. (1988) Antigen absorption by the jejunal epithelium of children with cow's milk allergy. Pediatr Res 24, 197-202.

282. Stene LC, Honeyman MC, Hoffenberg EJ, et al. (2006) Rotavirus infection frequency and risk of celiac disease autoimmunity in early childhood: a longitudinal study. Am J Gastroenterol 101, 2333-2340.

283. Matysiak-Budnik T, Candalh C, Dugave C, et al. (2003) Alterations of the intestinal transport and processing of gliadin peptides in celiac disease. Gastroenterology 125, 696-707.

284. Van Limbergen J, Wilson DC \& Satsangi J (2009) The genetics of Crohn's disease. In Annual Review of Genomics and Human Genetics vol. 10, pp. 89-116 [A Charavati and ED Green, editors]. Palo Alto, CA: Annual Reviews Inc.

285. Latiano A, Palmieri O, Valvano MR, et al. (2008) The association of $M Y O 9 B$ gene in Italian patients with inflammatory bowel diseases. Aliment Pharmacol Ther 27, 241-248.

286. Van Bodegraven AA, Curley CR, Hunt KA, et al. (2006) Genetic variation in myosin IXB is associated with ulcerative colitis. Gastroenterology 131, 1768-1774.

287. Monsuur AJ, de Bakker PIW, Alizadeh BZ, et al. (2005) Myosin IXB variant increases the risk of celiac disease and points toward a primary intestinal barrier defect. Nat Genet 37, 1341-1344. 
288. Foster DR, Landowski CP \& Welage LS (2002) Interferon- $\gamma$ increases dipeptide transport via increased expression of the oligopeptide transporter h-PEPT1 in cultured human intestinal monolayers. Pharmacotherapy 10, 1334.

289. Bryant RV, Brain O \& Travis SPL (2015) Conventional drug therapy for inflammatory bowel disease. Scand J Gastroenterol 50, 90-112.

290. Teml A, Schaeffeler E, Herrlinger KR, et al. (2007) Thiopurine treatment in inflammatory bowel disease: clinical pharmacology and implication of pharmacogenetically guided dosing. Clin Pharmacokinet 46, 187-208.

291. Darfeuille-Michaud A, Boudeau J, Bulois P, et al. (2004) High prevalence of adherent-invasive Escherichia coli associated with ileal mucosa in Crohn's disease. Gastroenterology 127, 412-421.

292. Wehkamp J, Harder J, Wehkamp K, et al. (2004) NF-кB- and AP-1-mediated induction of human $\beta$ defensin- 2 in intestinal epithelial cells by Escherichia coli Nissle 1917: a novel effect of a probiotic bacterium. Infect Immun 72, 5750-5758.

293. Moendel M, Schroeder BO, Zimmermann K, et al. (2009) Probiotic E. coli treatment mediates antimicrobial human $\beta$-defensin synthesis and fecal excretion in humans. Mucosal Immunol 2, 166-172.

294. Schlee M, Wehkamp J, Altenhoefer A, et al. (2007) Induction of human $\beta$-defensin 2 by the probiotic Escherichia coli Nissle 1917 is mediated through flagellin. Infect Immun $\mathbf{7 5}$, 2399-2407.

295. Kruis W, Frič P, Pokrotnieks J, et al. (2004) Maintaining remission of ulcerative colitis with the probiotic Escherichia coli Nissle 1917 is as effective as with standard mesalazine. Gut 53, 1617-1623.

296. Fiorino G, Danese S \& Peyrin-Biroulet L (2010) Anti-TNF therapy in inflammatory bowel diseases. In Clinical Update on Inflammatory Disorders of the Gastrointestinal Tract vol. 26, pp. 95-107 [J Mayerle and H Tilg, editors]. New York: Karger.

297. Blonski W \& Lichtenstein GR (2006) Complications of biological therapy for inflammatory bowel diseases. Curr Opin Gastroenterol 22, 30-43.

298. Rutgeerts P, Van Assche G \& Vermeire S (2004) Optimizing anti-TNF treatment in inflammatory bowel disease. Gastroenterology 126, 1593-1610.

299. Vermeire S, Noman M, Van Assche G, et al. (2003) Autoimmunity associated with anti-tumor necrosis factor $\alpha$ treatment in Crohn's disease: a prospective cohort study. Gastroenterology 125, 32-39.

300. Siegel CA, Hur C, Korzenik JR, et al. (2006) Risks and benefits of infliximab for the treatment of Crohn's disease. Clin Gastroenterol Hepatol 4, 1017-1024.

301. Khan KJ, Ullman TA, Ford AC, et al. (2011) Antibiotic therapy in inflammatory bowel disease: a systematic review and meta-analysis. Am J Gastroenterol 106, 661-673.

302. Madsen KL, Doyle JS, Jewell LD, et al. (1999) Lactobacillus species prevents colitis in interleukin 10 gene-deficient mice. Gastroenterology 116, 1107-1114.

303. Madsen K, Cornish A, Soper P, et al. (2001) Probiotic bacteria enhance murine and human intestinal epithelial barrier function. Gastroenterology 121, 580-591.

304. Triantafillidis JK, Merikas E \& Georgopoulos F (2011) Current and emerging drugs for the treatment of inflammatory bowel disease. Drug Design Dev Ther 5, 185-210.

305. Nielsen CU, Brodin B, Jorgensen FS, et al. (2002) Human peptide transporters: therapeutic applications. Expert Opin Ther Pat 12, 1329-1350.

306. Nielsen CU, Vabeno J, Andersen R, et al. (2005) Recent advances in therapeutic applications of human peptide transporters. Expert Opin Ther Pat 15, 153-166.
307. Rubio-Aliaga I \& Daniel H (2008) Peptide transporters and their roles in physiological processes and drug disposition. Xenobiotica 38, 1022-1042.

308. Knutter I, Theis S, Hartrodt B, et al. (2001) A novel inhibitor of the mammalian peptide transporter PEPT1. Biochemistry 40, 4454-4458.

309. Kovacs-Nolan J, Zhang H, Ibuki M, et al. (2012) The PepT1transportable soy tripeptide VPY reduces intestinal inflammation. Biochim Biophys Acta 1820, 1753-1763.

310. Dalmasso G, Charrier-Hisamuddin L, Nguyen HTT, et al. (2008) PepT1-mediated tripeptide KPV uptake reduces intestinal inflammation. Gastroenterology 134, 166-178.

311. Ito H, Takazoe M, Fukuda Y, et al. (2004) A pilot randomized trial of a human anti-interleukin-6 receptor monoclonal antibody in active Crohn's disease. Gastroenterology 126, 989-996.

312. Choy EHS, Isenberg DA, Garrood T, et al. (2002) Therapeutic benefit of blocking interleukin-6 activity with an antiinterleukin-6 receptor monoclonal antibody in rheumatoid arthritis: a randomized, double-blind, placebo-controlled, dose-escalation trial. Arthritis Rheum 46, 3143-3150.

313. Mitsuyama K, Sata M \& Rose-John S (2006) Interleukin-6 trans-signaling in inflammatory bowel disease. Cytokine Growth Factor Rev 17, 451-461.

314. Navas-López VM, Blasco-Alonso J, Maseri SL, et al. (2015) Exclusive enteral nutrition continues to be first line therapy for pediatric Crohn's disease in the era of biologics [article in Spanish]. An Pediatr 83, 47-54.

315. Konno M, Takahashi M, Toita N, et al. (2015) Long-term therapeutic effectiveness of maintenance enteral nutrition for Crohn's disease. Pediatr Int 57, 276-280.

316. Hirai $\mathrm{F}$, Ishihara $\mathrm{H}$, Yada $\mathrm{S}$, et al. (2013) Effectiveness of concomitant enteral nutrition therapy and infliximab for maintenance treatment of Crohn's disease in adults. Dig Dis Sci 58, 1329-1334.

317. Yamamoto T, Nakahigashi M, Umegae S, et al. (2010) Prospective clinical trial: enteral nutrition during maintenance infliximab in Crohn's disease. J Gastroenterol 45, 24-29.

318. Chiba M, Tsuji T \& Komatsu M (2014) Conflicting results on the efficacy of enteral nutrition during infliximab maintenance therapy for Crohn's disease are correct. Dig Dis Sci 59, 227-228.

319. Picariello G, Ferranti P, Fierro O, et al. (2010) Peptides surviving the simulated gastrointestinal digestion of milk proteins: biological and toxicological implications. J Chromatogr B Analyt Technol Biomed Life Sci 878, 295-308.

320. Schaafsma G (2009) Safety of protein hydrolysates, fractions thereof and bioactive peptides in human nutrition. Eur J Clin Nutr 63, 1161-1168.

321. Walker WA, Wu M, Isselbacher KJ, et al. (1975) Intestinal uptake of macromolecules 4. Effect of pancreatic duct ligation on breakdown of antigen and antigen-antibody complexes on intestinal surface. Gastroenterology 69, 1223-1229.

322. Terada T, Sawada K, Saito H, et al. (1999) Functional characteristics of basolateral peptide transporter in the human intestinal cell line Caco-2. Am J Physiol 276, G1435-G1441.

323. Terada T \& Inui K (2004) Peptide transporters: structure, function, regulation and application for drug delivery. Curr Drug Metab 5, 85-94.

324. Shepherd EJ, Lister N, Affleck JA, et al. (2002) Identification of a candidate membrane protein for the basolateral peptide transporter of rat small intestine. Biochem Biophys Res Comm 296, 918-922.

325. Irie M, Terada T, Okuda M, et al. (2004) Efflux properties of basolateral peptide transporter in human intestinal cell line Caco-2. Pflugers Arch 449, 186-194. 